\title{
Mechanisms Underlying the Anti-Depressive Effects of Regular Tea Consumption
}

\author{
Dylan O'Neill Rothenberg $(1)$ and Lingyun Zhang * (1) \\ Department of Tea Science, College of Horticulture Science, South China Agricultural University, \\ Guangzhou 510640, China; Dylan.Rothenberg@colorado.edu \\ * Correspondence: zhanglingyun@scau.edu.cn; Tel.: +86-02-85280542
}

Received: 8 May 2019; Accepted: 11 June 2019; Published: 17 June 2019

check for updates

\begin{abstract}
This article is a comprehensive review of the literature pertaining to the antidepressant effects and mechanisms of regular tea consumption. Meta-data supplemented with recent observational studies were first analyzed to assess the association between tea consumption and depression risk. The literature reported risk ratios (RR) were 0.69 with $95 \%$ confidence intervals of $0.62-0.77$. Next, we thoroughly reviewed human trials, mouse models, and in vitro experiments to determine the predominant mechanisms underlying the observed linear relationship between tea consumption and reduced risk of depression. Current theories on the neurobiology of depression were utilized to map tea-mediated mechanisms of antidepressant activity onto an integrated framework of depression pathology. The major nodes within the network framework of depression included hypothalamic-pituitary-adrenal (HPA) axis hyperactivity, inflammation, weakened monoaminergic systems, reduced neurogenesis/neuroplasticity, and poor microbiome diversity affecting the gut-brain axis. We detailed how each node has subsystems within them, including signaling pathways, specific target proteins, or transporters that interface with compounds in tea, mediating their antidepressant effects. A major pathway was found to be the ERK/CREB/BDNF signaling pathway, up-regulated by a number of compounds in tea including teasaponin, L-theanine, EGCG and combinations of tea catechins and their metabolites. Black tea theaflavins and EGCG are potent anti-inflammatory agents via down-regulation of NF-KB signaling. Multiple compounds in tea are effective modulators of dopaminergic activity and the gut-brain axis. Taken together, our findings show that constituents found in all major tea types, predominantly L-theanine, polyphenols and polyphenol metabolites, are capable of functioning through multiple pathways simultaneously to collectively reduce the risk of depression.
\end{abstract}

Keywords: Camellia sinensis; depression; inflammation; HPA axis; gut-brain axis; neurogenesis; neurotransmission; SCFA; EGCG; theaflavin; L-theanine

\section{Introduction}

Depression is the most common mental health condition in the general population [1,2], characterized by despondency, loss of motivation or pleasure, feelings of guilt or low self-esteem, poor appetite, insomnia, fatigue, and difficulty concentrating [3]. In extreme cases, depression can lead to suicide [4,5], and increase the risk of morbidity and all-risk mortality [6]. Depression can become an all-consuming disorder that affects occupational potential [7] and quality of life [8,9]. The World Health Organization (WHO) predicts that, by 2020, depression will rank second in global disease burdens and one of the priority conditions covered by the WHO's Mental Health Gap Action Programme [10].

Progress in the treatment of major depressive disorder (MDD) has been modest at best, in part because of the withdrawal of much of the pharmaceutical industry from the development of new psychotropic drugs [11]. Average estimates calculate that, among patients entering treatment for major 
depressive disorder (MDD), only about one third enter remission four months later [12]. With rates of MDD rising and treatments and efficacy of MDD treatments remaining stagnant, it is time to start looking elsewhere for ways to treat MDD. Some data have been encouraging for the ability of lifestyle changes to reduce risk of MDD such as less smoking [13], less alcohol consumption [14], fewer high-fat foods [15], and more exercise [16]. It has also been found that regular tea consumption has a strong linear relationship with reduced MDD [17]. This has led researchers to look more deeply into the mechanisms underlying the use of tea as an antidepressant agent.

Tea is the second most consumed beverage after water, mostly because it is an affordable luxury consumed by all socioeconomic classes around the world. As such, even minor benefits to mental or physical health could carry considerable implications for public health. Tea has been well established to confer a number of benefits, including anti-diabetic, anti-aging, pro-cardiovascular, and pro-metabolic effects [18-20]. The mechanisms of tea phytochemicals in reducing the risk of depression are complex and multidimensional, since neurologists and psychiatrists are coming to realize that depression itself is a multifaceted neurobiological pathology.

However, our understanding of depression is maturing, and new theories are emerging that allow us to see its deeper, more fundamental causes. Most data on the topic reflect that tea consumption can reduce risk of depression, but to date, no studies have used modern theories on depression pathology to provide comprehensive analysis of the mechanisms underlying these observations. Therefore, this report uses a current conceptual framework of depression neurobiology to provide detailed insight on the mechanisms underlying the observed antidepressant effects of tea consumption.

\section{Concept of Tea within an Integrative Theory of Depression}

Neuroimaging data have provided scientists with insights that have elucidated our understanding of the human brain. These insights have led to the development of an integrated theory of depression, in which multiple dysfunctional systems are viewed as a single interconnected pathology [21-23]. In the instance of an outdated theoretical model, for example the monoamine hypothesis, low monoamine levels (typically serotonin) is the cause of depression, and the way to treat the illness is by increasing circulating levels of serotonin. This treatment methodology has proven to be far too reductionist, and that is reflected in low efficacy rates of selective serotonin reuptake inhibitors (SSRIs) in long-term MDD treatment. The monoamine hypothesis fails to address what is responsible for the upstream causes of initial dysfunction within the serotonergic system, and thus simply supplying more serotonin has been shown to be an effective short-term alleviation of depressive symptoms, but not a long-term solution to the pathology.

A unified theory of depression, sometimes referred to as an integrated theory of depression, is one that underscores the interconnectivity among neurobiological systems involved in depression pathology, including inflammation, hypothalamic-pituitary-adrenal (HPA) axis activity, neurogenesis/neuroplasticity, and monoaminergic systems, including the gut-brain axis [23]. This article uses an integrative theory of depression pathology to explain the multitude of ways in which compounds in tea may be exerting anti-depressive effects in humans. Conceptually speaking, individual compounds in tea are not exerting potent pharmacological effects on individual neurobiological systems, as SSRIs do on the serotonergic system, but rather multiple constituents in tea, including L-theanine, L-arginine, polyphenols and their metabolites are collectively and simultaneously exerting modest effects within multiple neurobiological systems, leading to an overall significant net risk reduction in depression.

Thus, the primary focus of this paper is to review research detailing the mechanistic actions of tea compounds within neurobiological systems pertaining to depression, compare and contrast those findings, and map their functional significance within the larger network of integrated depression pathology. 


\section{Antidepressant Effects of Tea Consumption in the Literature}

In accordance with rigorous standards of research quality, 11 studies with 13 reports were selected for meta-analysis that evaluated the association between tea consumption and depression risk [17]. Meta-data were comprised of five cohort reports and eight cross-sectional reports, all of which yielded at least moderate quality assessment scores, averaged at good within Newcastle-Ottawa and Agency for Healthcare Research and Quality assessment scales. Studies included 22,817 participants with 4743 cases of depression, and a dose-response analysis of 10,600 participants with 2107 cases. This meta-analysis found that higher consumption of tea was associated with lower risk of depression. Dose-response analysis identified a negative correlation between tea consumption and depression risk, with every three cups/day increment in tea consumption associated with a $37 \%$ decrease in the risk [17]. A subgroup analysis was conducted to assess whether lifestyle factors such as physical exercise, smoking, alcohol consumption, etc. were confounding the results; however, similar results were obtained in these subgroup analyses. The aggregated risk ratio (RR) for studies measuring green tea $(n=3)$ was comparable to studies measuring "diverse tea types" $(n=5)$, which included oolong, black, white, and pu-erh teas, with RR (95\% confidence interval (CI)) of $0.67(0.56-0.79)$ and 0.69 (0.62-0.77) for green and diverse tea types, respectively.

In the meta-analysis of association in the 13 reports, all but one subgroup found similar results regarding associative risk. The inconsistent finding came from the population-based Kuopio Ischaemic Heart Disease Risk Factor Study taken between 1984 and 1989 and followed until the end of 2006, which investigated the association between intake of coffee, tea and caffeine and severe depression in middle-aged Finnish men [24]. No association was observed between severe depression and intake of tea in this study. However, this prospective study should be interpreted with caution, since it focused only on severe depression based on discharge diagnosis, which may have overlooked cases of mild and moderate depression in which patients were not hospitalized. Therefore, it is possible that this study was biased towards a null hypothesis. The meta-analysis by Dong et al. offered a brief mention of feasible mechanistic explanations for the results. However, it did not take into consideration comprehensive integrated views of depression pathology, perhaps because these theories on depression have only emerged in very recent years [21-23].

We conducted another search for high quality data measuring tea consumption and depression risk to supplement the meta-analytical data from Dong et al. [17] with more recent research. The MEDIS study published in May 2018 enrolled 2718 older individuals from 22 Mediterranean islands in cross-sectional sampling in the period of 2005-2011. A broad ranging set of dietary habits and socio-demographic characteristics were analyzed through cross-sectional examination for associations with depression [25]. Diet-related factors included consumption quantities and frequencies of fish, meat, vegetables, legumes, coffee, tea, and various alcoholic beverages. Factors such as age, education, financial status, physical activity, various blood lipid parameters and BMI were measured. Logistic regression model evaluating the various factors associated with depression found that daily tea consumption showed the lowest RR of any metric measured in the study (RR: 0.51 ; $95 \%$ CI; $0.40-0.65$, $p$ value $<0.001)$. The MEDIS study provided no detailed mechanistic explanation for the observed risk reduction resulting from daily tea consumption [25].

Using data from the Korean National Health and Nutrition Examination Survey, a total of 9576 (3852 men and 5725 women) aged 19 years or older were cross examined for associations between green tea consumption and self-reported depression [26]. Consumers of more than three cups/week had 21\% lower prevalence of depression $(R R=0.79,95 \% C I=0.63-0.99, p$ value $=0.0101)$ after adjusting for confounding factors. A weakness of this study was that the highest consumption bracket reported was three cups/week, when in fact several studies found significant differences in risk reduction between consuming three cups/week, considered moderate consumption, and one or more cups/day, considered high consumption. If this study had stratified between moderate and high consumption groups, it is possible there would have been lower RR for high consumption groups, as was the case in meta-data by Dong et al. [17]. 
Seventy-four healthy subjects participated in a double-blind, randomized placebo-controlled study with oral administration of green tea or placebo for five weeks, after which measurements were taken that included reaction time of reward responsiveness, and scores on the Montgomery-Asberg depression rating scale (MADRS) and 17-item Hamilton Rating Scale for Depression (HRSD-17) to estimate the depressive symptoms in these two groups. The results show chronic treatment of green tea increased reward learning compared with placebo by decreasing the reaction time in monetary incentive delay task. Moreover, participants treated with green tea showed reduced scores measured in MADRS and HRSD-17 compared with participants treated with placebo [27].

Taken together, these data suggest that regular daily tea consumption contribute to risk reduction in healthy individuals, and evidence was particularly strong among aging populations.

\section{Mechanistic Considerations}

Four primary nodes are named as mechanistic systems, which interrelate within a network of depression pathology: the HPA axis; immune inflammatory response; monoaminergic systems, which includes the gut-brain axis; and neurogenesis/neuroplasticity (Figure 1). These four nodes each have important subsystems within them, including signaling pathways, specific target proteins, or transporters that interface with compounds in tea, mediating their antidepressant effects. The healthy functioning of each node has the potential to be compromised by genetic or biological factors, representing poor "hardware" of these nodes, or by environmental stressors, learned behaviors, psychosocial stress, etc., representing poor "software" of this system [28]. Regardless of the upstream cause, when compromised, these nodes are able to reduce the functional capacity of other nodes through the formation of harmful positive feedbac k loops, creating an interrelated network of neuro-pathologies that can predispose MDD. Thus, the alleviation of depressive pathology within any single node has the capacity to reverberate through to other nodes, and similarly, targeting multiple nodes simultaneously may translate to significant risk reductions, which we hypothesize is the mode of action underlying the observed antidepressant effects of tea consumption. We call this the "reduce and restore" hypothesis, and the network nodal targets include reduction of HPA axis hyperactivity; reduction of inflammation; restoration of monoaminergic systems, including restoration of neurologically active gut microbiota; and restoration of neurogenesis/neuroplasticity.

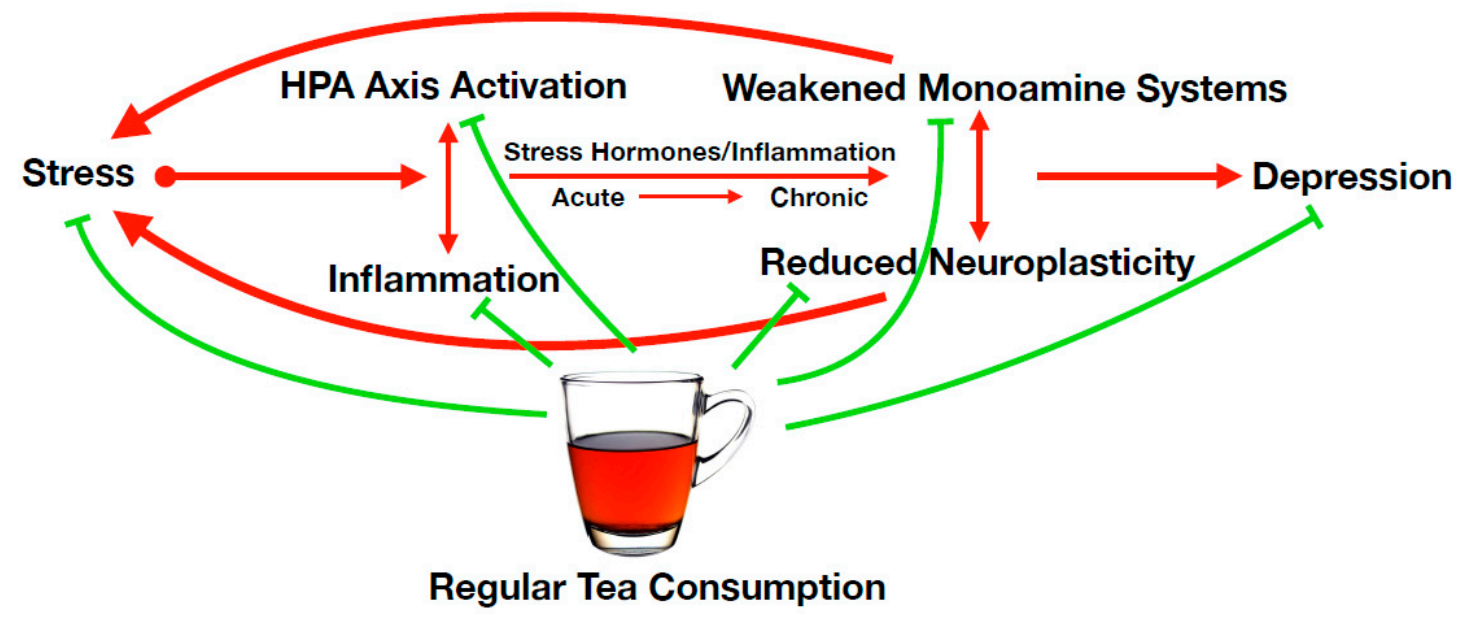

Figure 1. The effects of regular tea intake within a unified theory of depression pathology. External stressors induce an HPA-mediated stress response and inflammation. If acute stress and inflammation become a chronic, persisting physiological state, there can be detrimental effects on neuronal health and monoaminergic systems. Compromised cognitive emotional processing resulting from cumulative neuro-pathologies inhibits the ability to cope with future external stressors, re-feeding the state of chronic stress/inflammation. Green lines represent attenuating effect, while red lines represent exacerbating effect. HPA, hypothalamic-adrenal-pituitary. 


\subsection{Reduction of HPA Axis Hyperactivity}

The hypothalamic-pituitary-adrenal (HPA) axis is a feedback loop in which stress activates a hormonal pathway that induces a "fight-or-flight" response to a perceived threat. Due to its stress-induced nature, the HPA axis is referred to as the "stress circuit". Mechanistically speaking, when mammals experience stress, the hypothalamus releases corticotropin-releasing hormone (CRH). $\mathrm{CRH}$ then acts on the pituitary gland to trigger the release of adrenocorticotropin (ACTH) into the bloodstream. In response to $\mathrm{CRH}, \mathrm{ACTH}$ acts on the adrenal cortex by binding to the adrenal melanocortin 2 receptor (MC2R), which signals through cyclic AMP to stimulate the production and secretion of glucocorticoids (CORT). In humans, the primary CORT is cortisol, or known more colloquially as the "stress hormone". Two of cortisol's primary functions are promotion of gluconeogenesis in order to increase blood glucose levels, and the suppression of immune function. The HPA axis has considerable impact on an individual's mood at any given time, as this system communicates readily with other neurocircuitry in the brain, such as the limbic system, which serves to regulate mood and motivation.

Within a typical HPA axis response, the acute stressor will pass, and stress hormone cortisol will exert a negative feedback effect on the stress circuit by down-regulating CRH synthesis in the hypothalamus. However, unresponsiveness to cortisol's negative feedback signaling, or periods of constant perceived stress will cause the stress circuit to operate continuously, a physiological state referred to as HPA axis hyperactivity. Under such conditions, the limbic system is over-stimulated, leading to a condition of "learned helplessness", in which the overwhelmed subject loses motivation and detaches from external engagement, at which point in humans, depressive symptoms are reported and MDD is often diagnosed. Furthermore, with HPA hyperactivity, the hippocampus becomes desensitized to constant elevated levels of $\mathrm{CRH}$, causing the body to release more cortisol in an attempt to down-regulate $\mathrm{CRH}$ production. The elevated cortisol causes more stress and inflammation, in turn triggering the release of more cortisol, and the stress circuit becomes a positive feedback loop of neuropathology (Figure 2). Over time, chronic elevated stress hormone levels deteriorate important neural networks in the brain, including monoaminergic and limbic systems, and reduce hippocampal volume and neuroplasticity. As discussed below, these downstream effects can further exacerbate MDD neuropathology and symptomology. For these reasons, some have described MDD to be nearly synonymous with dysfunctional HPA axis activity $[29,30]$. This section reviews in vitro and in vivo studies measuring how the bioactive constituents in tea have been observed to affect HPA axis activity under stressful conditions, including the mechanistic explanations proposed for the observed effects (summarized in Table 1). 


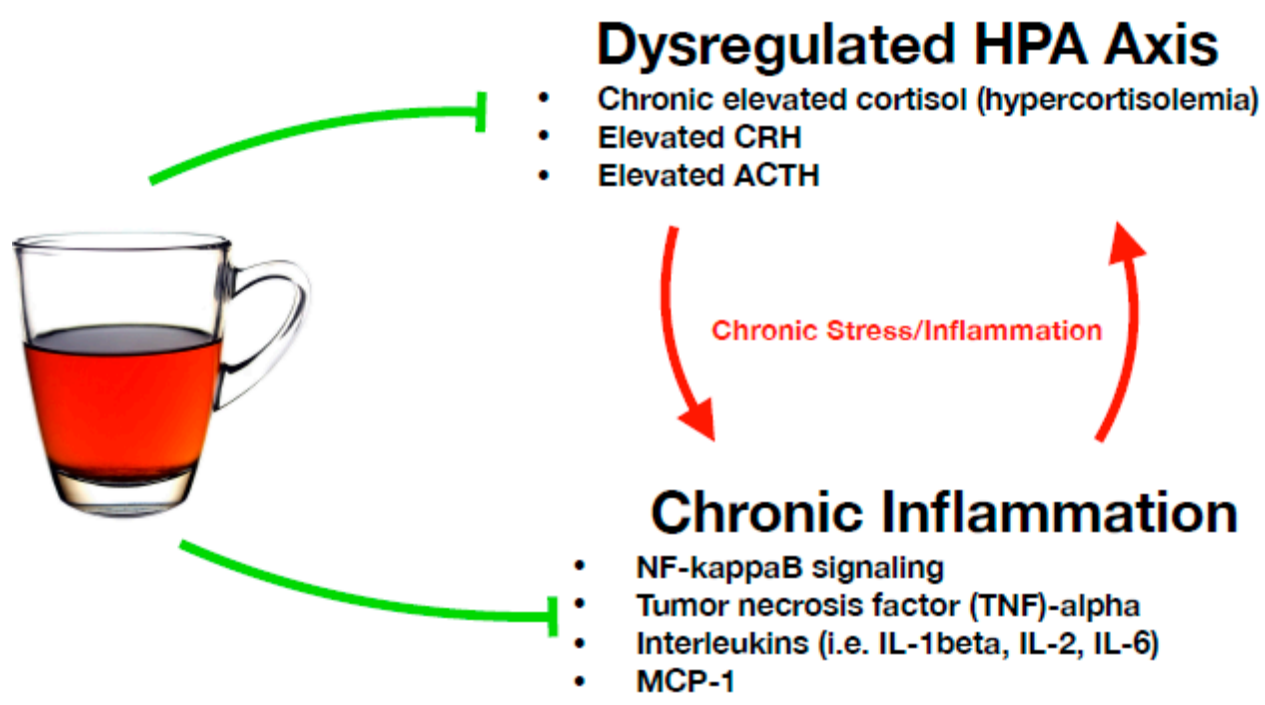

Figure 2. The positive feedback loop of chronic stress and inflammation. Dysregulated HPA axis and chronic inflammation represent two mechanistic nodes within an interrelated system of depression pathology. Bullet points represent signaling pathways and pathological targets for tea phytochemicals. Green lines represent attenuating effect, while red lines represent exacerbating effect. HPA, hypothalamic-pituitary-adrenal; $\mathrm{CRH}$, corticotropin-releasing hormone; $\mathrm{ACTH}$, adrenocorticotropin hormone; MCP-1, monocyte chemoattractant protein-1.

Table 1. Tea compounds and their effects on physiological stress-response.

\begin{tabular}{|c|c|}
\hline Tea Compound & Effect on Physiological Stress Response \\
\hline L-theanine & $\begin{array}{c}\text { Reduction in stress as measured by attenuated adrenal hypertrophy [31] } \\
\text { Reduced sAA and subjective stress levels [32] Reduction in elevated } \\
\text { plasma ACTH and CORT [32,33] }\end{array}$ \\
\hline L-arginine & Reduction in stress as measured by attenuated adrenal hypertrophy [31] \\
\hline Green tea polyphenol mixture & $\begin{array}{l}\text { Reduced CORT and ACTH, reduced immobility in FST and TST [34] } \\
\text { Restored HPA activity via ERK upregulation [35] }\end{array}$ \\
\hline EGCG (anti-stress effects) & $\begin{array}{c}\text { Restored HPA activity via ERK upregulation [35] Lowered } \\
\text { corticosterone/CRH/ACTH [36] stress-reduction via reduction of neuron } \\
\text { over-excitation [37-39] improved GABA transmission via activation of } \\
\text { the SIRT1/PGC-1 } \alpha \text { pathway [40] Antagonized stress-reduction effects of } \\
\text { L-theanine/L-arginine [31] }\end{array}$ \\
\hline Epigallocatechin & $\begin{array}{l}\text { Restored anti-stress effects of L-theanine/L-arginine [31] through } \\
\text { competitive inhibition of EGCG [31] }\end{array}$ \\
\hline Low-Caffeine Green Tea & $\begin{array}{l}\text { Lowered sAA levels, improved sleep quality more effectively than } \\
\text { standard caffeinated green tea [41] Reduction in adrenal hypertrophic } \\
\text { stress response, more significant than standard green tea [31] }\end{array}$ \\
\hline Green Tea, Shade-Grown White Tea & $\begin{array}{c}\text { Lowered CgA levels following stress load task for both tea types, more } \\
\text { effect for Shade-Grown White Tea [42] }\end{array}$ \\
\hline Green Tea Aroma & Lowered CgA levels following stress load task [43] \\
\hline Black Tea Aroma & Lowered CgA levels following stress load task [44] \\
\hline
\end{tabular}

sAA, salivary $\alpha$-amylase; ACTH, adrenocorticotropin hormone; CORT, glucocorticoids; FST, forced swimming test; TST, tail suspension test; HPA, hypothalamic-pituitary-adrenal; ERK, extracellular signal-regulated kinase; $\mathrm{CRH}$, corticotropin-releasing factor; GABA, gamma-aminobutyric acid; SIRT1, sirtuin 1; PGC-1 $\alpha$, peroxisome proliferator-activated receptor gamma (PPAR $\gamma$ ) coactivator- $1 \alpha$; EGCG, epigallocatechin gallate.

A recent study intraperitoneally injected ICR mice with L-theanine $(20 \mathrm{mg} / \mathrm{kg})$ for seven days before a single intraperitoneal injection of lipopolysaccharide (LPS) to induce an inflammatory stress response. The LPS treatment caused a significant increase in circulating ACTH and CORT, and 
pretreatment with L-theanine significantly attenuated this response. The proposed mechanism was a modulatory interaction between theanine and glucocorticoid receptors (GR), although the immediate regulating action of theanine on GR was said to be unknown [33].

Wang et al. [32] conducted another experiment similarly testing the effects of L-theanine on HPA activity, however theanine was administered intragastrically, and stress was induced in mice by whole body heat shock rather than LPS. Heat shock is a stress-induction method that has been shown to activate HPA activity and increase CORT levels in previous in vivo experiments [45]. L-theanine supplementation normalized the heat stress-induced HPA axis hyperactivity by significantly reducing elevated plasma ACTH and CORT levels compared to control. Wang et al. [32] suggested that theanine might have been able to participate in crosstalk between inflammatory cytokines and the HPA axis, but commented that the immediate mechanism of HPA regulatory activity was uncertain.

Some studies have suggested that a potential mechanism by which L-theanine can normalize HPA hyperactivity is through the antagonistic effect on glutamate. Glutamate is the primary excitatory neurotransmitter in the central nervous system, critical to HPA axis activation [46], reflected in studies where glutamate agonists activated the HPA axis in rats by inducing ACTH elevation [47]. L-theanine incorporated into the brain is reported to reduce the release of glutamate from pre-synapse to the synaptic cleft [48], where glutamate can then be decarboxylized into gamma-aminobutyric acid (GABA), the brain's main inhibitory neurotransmitter. In support of this mechanistic explanation, one study measured the hippocampus of mice that ingested theanine $(6 \mathrm{mg} / \mathrm{kg})$ in drinking water for two weeks, finding that the levels of glutamate and pyroglutamic acid were significantly reduced, and GABA increased [49], suggesting that theanine modulated GABA production via glutamate inhibition. This proposed pathway would provide stress reduction benefits that are twofold: reducing HPA axis activation through reduction of activator glutamate, and increasing the circulating levels of GABA, which has been shown to provide anti-stress/anxiolytic effects. It remains debatable whether GABA synthesized outside the brain is able to cross the blood-brain barrier (BBB) in quantities with relevance to in cerebro neurotransmission [50], which suggests that up-regulation of GABA synthesis in the brain could be an important contribution of L-theanine to lowering stress and normalizing HPA axis activity.

Green tea polyphenols (GTP) without L-theanine orally administered in doses of 5, 10 and $20 \mathrm{mg} / \mathrm{kg}$ for seven days showed antidepressant-like effects in a mouse model of depression [34]. Following GTP supplementation, serum corticosterone, the primary CORT in rodents, and ACTH levels were reduced in mice exposed to forced swimming tests (FST). GTP also significantly reduced immobility in FST and tail suspension tests (TST), suggesting that tea polyphenols may possess the ability to normalize stress-induced HPA activity and provide antidepressant effects through this pathway.

Both L-theanine and tea polyphenols have been shown capable of attenuating HPA-mediated responses when ingested individually, however one study showed that these compounds acted antagonistically regarding their effects on stress response. Unno et al. [31] measured stress responses in mice following consumption of three types of green tea in a model of psychosocial stress induced by confrontational housing. Adrenal hypertrophy was used as a biomarker for stress response, which is common among studies measuring HPA activity in living organisms [51,52]. This study found that two tea types, theanine-rich Gyokuro and low-caffeine Sencha, significantly reduced adrenal hypertrophy in stressed mice, while the third tea type, normal Sencha, reduced stress levels at an insignificant rate compared to the water control. The reason for this effect was discovered to be that not only caffeine, but also epigallocatechin gallate (EGCG) were both effective at suppressing anti-stress effects of L-theanine. Interestingly, epigallocatechin (EGC), the non-gallate form of EGCG, was found to block the antagonistic effects of EGCG against L-theanine, effectively preserving the anti-stress effects of theanine. EGC was able to do this through competitive inhibition of EGCG uptake into the brain. A competitive inhibitory relationship was assumed as the blood-brain permeability of EGCG was significantly lowered by the same molar amount of EGC using a BBB model. By lowering the incorporation of EGCG into the brain, EGC lowered the antagonistic effects of EGCG against L-theanine. EGC itself, however, was not shown to inhibit the anti-stress effects of L-theanine. This 
may be because efflux transporters expressed on the cell membrane have been shown to be actively suppressed by the presence of a gallate moiety [53-55], meaning that EGC effluxed more easily out of cell membranes, and was thus less able to interfere with L-theanine.

No studies to date have proposed a mechanistic explanation of how EGCG may have interfered with the anti-stress effects of L-theanine; however, we propose here an original hypothesis for this observed effect. It has been suggested that L-theanine has another pathway of conferring anti-stress effects in addition to the pathway involving decarboxylation of glutamate into GABA. It was suggested by Yamada et al. that theanine was able to act directly on $\alpha$-amino-3-hydroxy-5-methyl-4-isoxazolepropionic acid (AMPA) receptors, ionotropic glutamate receptors in the brain, and in rats, action upon AMPA receptors by L-theanine lead to significantly increased glycine concentration in the striatal interstitium [56]. Glycine is a major inhibitory neurotransmitter in the spinal cord and brainstem responsible for processing motor and sensory information, functioning in the CNS similarly to, and simultaneously with GABA [57,58]. In addition to the anxiolytic effects normally attributed to inhibitory neurotransmitters, glycine also induces the release of dopamine (DA) [59], which may explain at least part of the reported mood-enhancing effects of L-theanine [60]. In the pathway described above, L-theanine acts on AMPA receptors, causing the release of glycine, which subsequently acts on glycine receptors, triggering the release dopamine. However, it was shown that EGCG significantly modulated AMPA receptor activity by inhibiting calcium influx into the neuronal cell [37]. The effect of EGCG on AMPA receptors were similar to CNQX, a competitive antagonist of AMPA receptors [61]. In these two studies, the overall effect of EGCG on AMPA receptors was neuroprotective in nature, as EGCG effectively prevented excitotoxicity induced by high concentrations of an AMPA agonist. However, we hypothesize that EGCG may be competing with L-theanine for AMPA receptor binding sites, or through some other mechanism impeding its affinity for AMPA receptor activity, and through this mechanism lowering the total net anti-stress effect conferred by theanine. Thus, our original "AMPA hypothesis" posits that gallated polyphenols in tea may be capable of reducing anti-stress effects of L-theanine via competitive inhibition of AMPA receptor binding sites. Thus far, EGCG is the only gallated tea polyphenol with data regarding its AMPA receptor-modulating potential or capacity to inhibit anti-stress effects of L-theanine, however other gallated tea polyphenols such as ECG, EGCG3"Me, or theaflavin-3,3'-digallate may serve as interesting targets of future research regarding said effects.

The antagonistic effect of caffeine against theanine-induced stress reduction was tested in humans using green tea with lowered caffeine content (LCGT) in a group of middle-aged individuals ( $n=$ 20 , mean age $51.3 \pm 6.7$ years) in a double-blind crossover design with standard green tea (SGT) as a control [41]. A non-invasive biomarker for stress was utilized, which measured the body's alternate system for mediating stress response other than the HPA axis, the sympathetic branch of the autonomic nervous system (ANS). Salivary $\alpha$-amylase (sAA), a digestive enzyme in the mouth, has been shown to be a useful tool in measuring ANS reactivity to stress [62] because it rapidly increases in response to physiological and psychosocial stress [63-65]. The results of the human trial showed that sAA levels were considerably lower in the participants who consumed LCGT compared to those that consumed SGT, suggesting that caffeine reduced anti-stress effects of L-theanine. This study also found that sleep quality improved significantly with LCGT compared to SGT, which is relevant to depression, as sleep disturbances have been shown to act a precursor to the development of depression [66]. This finding corroborates with other research reporting the ability of L-theanine to improve sleep duration and sleep quality, particularly when ingested together with GABA, an amino acid found in high quantities in teas processed under certain conditions [67,68]. Unno et al. [41] elucidated the importance of low relative caffeine content in mediating the ability of tea consumption to improve sleep and reduce bodily systemic responses to everyday stress. It is worthwhile to note, however, that, although caffeine may reduce anti-stress effects of tea, some studies show that certain tea compounds, such as polyphenols, theobromine and L-theanine, can enhance mood and cognitive effects of caffeine and alleviate negative psychophysiological effects of caffeine [60], which may confer added benefits to university students, 
among whom $92 \%$ reported to have consumed caffeine in the past year in a geographically-dispersed sample of United States university students [69].

Reduced sAA levels $(p=0.032)$ and lower subjective stress levels $(p=0.020)$ were reported among fifth-year university students $(n=20)$ who consumed $200 \mathrm{mg}$ of theanine twice per day [70]. Similarly, green and white tea consumption decreased levels of salivary chromogranin A (CgA), an ANS-mediated indicator of stress level, among university students $(n=18)$ performing mental stress load tasks in a randomized cross-over design study [42]. CgA was also found to decrease in two studies that exposed university students to the aromas of black or green tea prior to taking 30-min mental stress load tasks [43,44]. The inhalation of both types of tea aroma induced lower CgA levels following stress load tasks.

Zhao et al. [35] found that administration of EGCG or a GTP mixture was associated with partial restoration of normal plasma CORT levels in mice following four-week restraint stress-induced HPA hyperactivity. The primary mechanism of CORT reduction was said to be upregulation of extracellular signal-regulated kinase (ERK)1/2 signaling pathways, which was induced significantly by EGCG treatment and to a lesser extent by GTP [35]. This is a fascinating finding in light of increasing evidence suggesting that ERK pathway suppression may be critically linked to the development of depression [71,72]. It was shown that ERK1/2 is highly sensitive to stress and closely related to cognition and mood processing [73]. Moreover, ERK1/2 was found to be significantly reduced in post-mortem brains of suicide victims [74]. Multiple data have shown that EGCG and GTP mixtures can inhibit HPA activity and improve neurological status in mice via activation of the ERK pathway [35,75]. However, it remains unclear if the anti-depressive effects of ERK are predominantly due to ERK itself, or by the phosphorylation of its downstream substrate, cyclic AMP response element binding protein (CREB), or by the consequent upregulation of its further downstream target, brain-derived neurotrophic factor (BDNF). BDNF is a key promoter of hippocampal neurogenesis, and represents another target in combating MDD, which is discussed in more detail when reviewing the role of tea compounds in neurogenesis and neuroplasticity.

In corroboration with the findings of ERK activation by EGCG and GTP, a recent study found that intraperitoneally injected EGCG $(25 \mathrm{mg} / \mathrm{kg}$ ) for 14 days prior to a single prolonged stress (SPS) was able to significantly decrease the SPS-stimulated increase in plasma corticosterone levels, and significantly attenuate SPS-induced increases in plasma CRH and ACTH levels. These changes were accompanied by attenuated CREB/BDNF levels, and attenuation of ameliorated cognitive ability and object recognition memory in behavioral tests. This study provides evidence of an up-regulated ERK/CREB/BDNF pathway working in unison with normalized HPA axis activity to mediate antidepressant activity of EGCG [36].

Johnston proposed a hypothesis for the mechanism of EGCG's anxiolytic effect that included direct binding to the benzodiazepine binding site of GABA receptor complexes [76]. In doing so, EGCG may be able to displace endogenous negative modulators of the GABA receptor. In theory, this makes sense, as the presence of endogenous negative modulators of the benzodiazepine binding site of GABA receptors have been found to exist in rats [77]. These polypeptide compounds possessed diazepam-binding inhibition (DBI) properties in the hippocampi of rats, where they elicited "proconflict" responses. EGCG could be working to restore full GABA receptor function by the displacement of DBI-type anxiogenic ligands [76].

As mentioned above, EGCG was able to antagonize AMPA glutamate receptors in mice, decreasing neuronal excitotoxicity through that mechanism [37], albeit that may have lowered total anti-stress effects by interfering with L-theanine. Neuroprotective effects via attenuated over-excitation in neurons has been reported for EGCG in several studies [38,78]. Hypothalamic infusion of EGCG in rats [31] lowered glutamate and norepinephrine levels, and increased GABA levels in the paraventricular nucleus (PVN), indicating attenuated ANS stress-response, coinciding with a more balanced environment of circulating excitatory and inhibitory neurotransmitters [39]. 
The SIRT1/PGC-1 $\alpha$ signaling pathway was proposed as another mechanism through which EGCG was able to attenuate stress-response via the normalization of excitatory and inhibitory neurotransmitters [40]. PGC- $1 \alpha$ (peroxisome proliferator-activated receptor gamma (PPAR $\gamma$ ) coactivator- $1 \alpha$ ) is a key regulator of cellular energy metabolism in the brain, found to be markedly declined in stressed animals, and significantly attenuated by EGCG and GTP treatments $[35,40,79]$. PGC- $1 \alpha$ regulates the expression of transcriptional factors involved in energy metabolism and inflammation in high energy demand tissues, such as the cerebrum. In recent studies on mice, PGC- $1 \alpha$ activation was found to mediate improvements in stress management [80] and reduction of depressive behavior [81]. The anxiolytic effects of PGC- $1 \alpha$ are due to its role in GABA neurotransmission, wherein deletion of PGC- $1 \alpha$ was found to promote asynchronous GABA release $[82,83]$. For these reasons, the EGCG- and GTP-induced enhancement of PGC- $1 \alpha$ expression in the brain of stressed animals may be critical to mediating their effects on neurotransmission, stress and depression.

Taken together, preliminary results appear to be promising regarding the effects of tea compounds on dysregulated stress-response systems, although more data are necessary to understand their effects in humans, particularly given the sensitivity of L-theanine's effects to caffeine and EGCG. Notable among the stress-response normalization pathways of tea are glutamatergic antagonism, GABAergic pathway protection, and attenuation of ERK1/2 signaling and PGC- $1 \alpha$ signaling. However, several studies reported that the mechanisms underlying attenuated stress-responses are unknown, highlighting the need for more research in this field.

\subsection{Reducing Inflammation}

Inflammation is triggered by the release of inflammatory cytokines such as interleukin (IL)-1 $\beta$ IL-2, IL-6, tumor necrosis factor alpha (TNF- $\alpha$ ), and C-reactive protein (CRP), which all have been found to be up-regulated in patients with depression $[84,85]$. The relationship between inflammation and depression can be traced in part back to an adaptive trait called "sickness behavior", in which humans who are attempting to fight infection reduce participation in activities such as exploration or seeking mates, which compete with an active immune system for energy stores [86]. For an acute infection during evolutionary times, behaviors of anhedonia, fatigue, and internal focus allowed one to allocate bodily resources to the immune system, which can consume $30 \%$ of basal metabolic rate during an immune response. However, in cases of chronic inflammation, which can come as a result of poor sleep, poor diet, smoking, lack of exercise, psychological stress, or a number of other lifestyle factors, sickness behavior can persist indefinitely, no longer serving its evolutionary purpose [87].

Additionally, inflammation coincides with a significant decrease in serotonin levels. The mechanistic explanation is that serotonin synthesis and bacterial growth both depend on tryptophan as a precursor. The immune system attempts to arrest bacterial growth by up-regulating a metabolic pathway that metabolizes tryptophan into kynurenine (KYN) via the enzyme indoleamine 2,3-dioxygenase (IDO). Inflammatory cytokines induce IDO activity, causing a significant drop in tryptophan levels and a corresponding decline in serotonin synthesis. The KYN pathway might not necessarily be a part of sickness behavior, however low serotonin levels resulting from inflammation almost certainly exacerbate depression symptomology.

Finally, inflammatory cytokines can boost cortisol levels and activate the HPA axis, which is in turn inflammatory. As discussed in the previous section, inflammation can form a positive feedback loop with the HPA axis, creating a state of chronic stress and inflammation, leading to the deterioration of important neural networks in the brain, such as the monoaminergic and limbic systems, and hippocampal neuroplasticity. For these reasons, reducing inflammation has become a critical target in the treatment of depression [11,88-90]. Here, we review in vitro and in vivo studies that have measured the effect on inflammation of ingesting tea or individual bioactive compounds in tea, including the mechanistic explanations proposed for the observed effects (summarized in Table 2). 
Table 2. Various tea compounds and their anti-inflammatory effects.

\begin{tabular}{|c|c|}
\hline Tea Compound & Effect on Inflammatory Response \\
\hline Theaflavins (TF) & $\begin{array}{l}\text { Reduced LPS-induced neural inflammation, suppressed cytokine production, } \\
\text { reduced immobility in TST. TF showed better anti-inflammatory capacity than } \\
\text { common polyphenols, but comparable to EGCG [91]. }\end{array}$ \\
\hline Theaflavin-3,3'-digallate (TF3) & Inhibited LPS-induced expression TNF- $\alpha$, IL-1 $\beta$, and IL-6 $[92,93]$ \\
\hline Green Tea Extract & $\begin{array}{l}\text { Reduced hepatic inflammation by attenuating NFKB activation via } \\
\text { down-regulation on TNFR1 and TLR4 in HFD model [94] }\end{array}$ \\
\hline Epigallocatechin gallate (EGCG) & $\begin{array}{l}\text { Reduced neuroinflammation via inhibition of MAPK and NFKB pathways in } \\
\text { HFFD model [95]. Reduced SPS-induced increase in IL-1 } \beta \text { and TNF- } \alpha \text { in } \\
\text { mouse hippocampi, decreased expression level of IL-1 } \beta \text { mRNA with RT-PCR } \\
\text { analysis [36]. Downstream inhibitor of inflammatory signaling through } \\
\text { occupation of TAK1 site, inhibition of p38 and NFKB [96]. Reduced } \\
\text { CSM-induced IL-8 production via inhibition of p38, MAPK and NFKB in } \\
\text { AC16 cardiomyocytes [97]. Inhibited phosphorylation of p65, showed in vitro } \\
\text { NFkB regulation [98]. Inhibited activity of NO, COX-2, TNF- } \alpha \text {, IL- } 6 \text { and IL-1 } \beta \\
\text { in LPS-induced murine macrophage cell line [99] In cultured human } \\
\text { epidermal keratinocytes exposed to airborne PM10, suppressed TNF- } \alpha, \text { IL-1 } \beta \text {, } \\
\text { IL-6, IL-8 and MMP-1 [100]. Topical application in 8-week RCT improved } \\
\text { acne via suppression of NFKB/AP-1 pathway [101] }\end{array}$ \\
\hline EGC and EC & $\begin{array}{l}\text { Effective downstream inhibitors of inflammatory signaling through } \\
\text { occupation of TAK1 site [96] }\end{array}$ \\
\hline Gallic acid & $\begin{array}{c}\text { Reduced airway inflammation by decreasing IL-4, IL-5, IL-13, IL-17 in nasal } \\
\text { lavage fluid of mice with allergic rhinitis [102] }\end{array}$ \\
\hline Gallocatechin gallate & $\begin{array}{l}\text { Inhibited LPS-induced expression of MCP-1 and IL-6 as effectively as EGCG } \\
\text { in 3T3-L1 cells [98]. }\end{array}$ \\
\hline Oolong tea ethanol extract & $\begin{array}{l}\text { Inhibited activity of NO, COX-2, TNF- } \alpha \text {, IL- } 6 \text { and IL-1 } \beta \text { in LPS-induced } \\
\text { murine macrophage cell line [99] }\end{array}$ \\
\hline L-theanine & $\begin{array}{c}\text { Topically delivered, reduced skin inflammation via inhibition of IL-1 } \beta, \text { TNF- } \alpha \\
\text { and COX-2 [103]. Alleviated airway inflammation via suppression of NFKB } \\
\text { pathway, reduced production of MCP-1, IL-4, IL-5, IL-13, TNF- } \alpha \text { and } \\
\text { interferon-gamma, attenuated trafficking of inflammatory cells into } \\
\text { bronchoalveolar lavage fluid [104]. }\end{array}$ \\
\hline Teasaponin & Attenuated TLR-4, NF- $\kappa$ B, IL-1 $\beta$, IL-6 and TNF- $\alpha$ in HFD mouse model [105]. \\
\hline
\end{tabular}

NO, nitric oxide; COX-2, cyclooxygenase-2; TNF- $\alpha$, tumor necrosis factor alpha; IL, interleukin; LPS, lipopolysaccharide; NFkB, nuclear factor kappa-light-chain-enhancer of activated B cells; RT-PCR, reverse transcription polymerase chain reaction; MCP-1, monocyte chemoattractant protein-1; HFD, high-fat diet; EGCG, epigallocatechin gallate; MAPK, mitogen-activated protein kinase; TNFR1, TNF receptor 1; TLR4, Toll-like receptor 4; HFFD, high-fat/high-fructose diet; EGC, epigallocatechin; EC, epicatechin.

In mice with LPS-induced neural inflammation, black tea theaflavins (TF) suppressed production of inflammatory cytokines and significantly reduced depression-like behavior, as measured by reduced immobility in the TST [91]. Interestingly, this study compared the anti-inflammatory activity of TF to that of catechin, EGCG, chlorogenic acid, and caffeic acid at concentrations of $0,1,3,10$, and $30 \mu \mathrm{M}$. The results indicate that the anti-inflammatory activities of TF on microglia are stronger than those of common polyphenols, but comparable to EGCG. In two more in vivo studies, theaflavin-3,3'-digallate (TF3) significantly inhibited LPS-induced expression of several inflammatory biomarkers, including TNF- $\alpha$, IL-1 $\beta$, and IL-6 $[92,93]$. These data indicate that black tea TFs may be effective anti-inflammatory agents with comparable efficacy to EGCG.

In a high-fat diet (HFD) mouse model, green tea extract (GTE) treatment reduced hepatic inflammation by decreasing pro-inflammatory signaling through TNF receptor-1 and Toll-like receptor (TLR)-4, which in non-GTE HFD mice increased nuclear factor kappa-light-chain-enhancer of activated $B$ cells (NFKB) activation, and consequent liver injury [94]. NF- $k B$ is a protein complex involved in cellular responses to stress and inflammation, and controls transcription of DNA, cytokine production and cell survival. The NF- $\mathrm{kB}$ pathway, in addition to another potentially inflammatory pathway, the mitogen-activated protein kinase (MAPK) pathway, were found to be down-regulated following 
EGCG supplementation in a high-fat/fructose diet (HFFD) mouse model [95]. Similarly, teasaponin, another major active component in tea, delivered orally $(0.5 \%)$ mixed in HFD for eight weeks was found to attenuate inflammatory markers in mice hippocampi, including TLR-4, NF-kB, IL-1 $\beta$, IL-6 and TNF- $\alpha$ [105]. These data suggest that several active compounds in tea may be effective in attenuating inflammation resulting from high-fat diets.

In corroboration with these findings, Lee et al. [36] found that intraperitoneally injected EGCG ( $25 \mathrm{mg} / \mathrm{kg}$ ) for 14 days prior to a single prolonged stress (SPS) was able to decrease the SPS-induced increases of IL-1 $\beta$ and TNF- $\alpha$ levels in the hippocampi of mice, which was associated with ameliorated cognitive ability and object recognition memory during behavioral tests. Additionally, reverse transcription polymerase chain reaction (RT-PCR) revealed that the EGCG group showed significantly decreased expression levels of IL-1 $\beta$ mRNA compared to non-EGCG group, lending support to the mechanistic explanation that EGCG exerts anti-inflammatory effects via down-regulation of one or more inflammatory nuclear signaling pathways [36].

EGCG was shown to function as a more effective downstream inhibitor of inflammatory signaling compared to EGC and epicatechin (EC) [96]. Molecular docking analysis confirmed that while EGCG, EGC and EC were all able to occupy most of the TGF $\beta$ activated kinase 1 (TAK1) active site, a key inflammatory signaling node, only EGCG could also inhibit NFKB expression and p38 kinase, a key regulator in the inflammatory pathway.

Human AC16 cardiomyocytes were pre-treated in vitro with EGCG $30 \mathrm{~min}$ before $4 \%$ cigarette smoke medium (CSM) was added to induce inflammation. EGCG treatment reduced CSM-induced inflammatory chemokine IL-8 production in the supernatant via the inhibition of ERK1/2, p38 MAPK and $\mathrm{NF} \kappa \mathrm{B}$ activation in AC16 cardiomyocytes [97]. It is interesting to note that down-regulating the ERK pathway in this study induced anti-inflammatory effects, while up-regulation of ERK has recently been identified as a primary target for antidepressants [71]. As a cellular pathway, ERK functions to communicate a signal from a receptor on the surface of the cell to the DNA in the nucleus, and as such can serve a multitude of functions, including the proliferation of inflammatory cytokines, or the potentiation of BDNF. Although currently in its early stages, the literature regarding the role of ERK signaling in depression pathology suggests that ERK more often represents a target for up-regulation in the context of BDNF-induced neurogenesis, rather than a target for down-regulation in the context of mediating inflammation. It is unclear at this time whether EGCG is capable of modulating multiple ERK pathways in different directions simultaneously, or what the net effect of EGCG-mediated ERK modulations is, considering the vast complexity of external signals that this pathway proliferates.

Aside from EGCG and TF3, multiple other tea constituents have shown significant anti-inflammatory activity include gallic acid (GA), gallocatechin gallate (GCG), oolong tea extract, and L-theanine. GA reduced airway inflammation by decreasing the levels of IL-4, IL-5, IL-13 and IL-17 in nasal lavage fluid of mice with allergic rhinitis [102]. GCG, a tea catechin found in abundance in ready-to-drink (RTD) tea drinks, was found to inhibit LPS-induced expression of monocyte chemoattractant protein-1 (MCP-1) and IL-6 as effectively as EGCG in differentiated 3T3-L1 cells treated with LPS for $6 \mathrm{~h}$ [98]. It was found that GCG and EGCG both inhibited the LPS-induced phosphorylation of $\mathrm{p} 65$, and showed similar in vitro capacity to regulate NFKB activation.

Oolong tea ethanol extract (OTEE) showed comparable anti-inflammatory activity to EGCG by reducing several inflammatory responses in LPS-induced murine macrophage cell line (RAW 264.7) [99]. This study found that, compared to a positive control group, OTEE and EGCG exhibited inhibitory activity toward levels of nitric oxide (NO), cyclooxygenase-2 (COX-2), TNF- $\alpha$, IL-6 and IL-1 $\beta$. Both OTEE and EGCG suppressed production of all of the aforementioned inflammatory cytokines and modulators; however, OTEE had higher inhibition activity than EGCG toward NO, COX-2, IL-6 and IL- $1 \beta$, while the reverse was true for TNF- $\alpha$. This lends support to the notion that chemical differences resulting from tea processing can cause metabolites to behave differently within certain specific pathways, yet produce similar net effects on larger target systems of antidepressant activity. 
One dose of topically delivered L-theanine was shown to reduce acute skin inflammation in a mouse model by inhibiting production of IL-1 $\beta$, TNF- $\alpha$ and COX-2 [103]. An ovalbumin-induced murine model of asthma showed that L-theanine alleviated airway inflammation and dramatically attenuated extensive trafficking of inflammatory cells into bronchoalveolar lavage fluid (BALF) [104]. This study found L-theanine administration significantly decreased the production of MCP-1, IL-4, IL-5, IL-13, TNF- $\alpha$, and interferon-gamma in BALF, exhibiting strong anti-inflammatory activity through suppression of the NFKB pathway.

Human skin, in the form of cultured human epidermal keratinocytes, were treated with EGCG $(3 \sim 10 \mu \mathrm{M})$ and exposed to airborne particulate matter PM10 $(100 \mu \mathrm{g} \mathrm{mL}-1)$ in a study that showed anti-inflammatory effects of topical EGCG via suppression of PM10-induced TNF- $\alpha$, IL-1 $\beta$, IL-6, and IL-8 [100]. Another topical skin study found that anti-inflammation through the suppression of the $\mathrm{NF} \kappa \mathrm{B}$ /activator protein 1 (AP-1) pathway contributed to significantly improved acne in an eight-week randomized, split-face, human clinical trial using topical application of 1 and 5\% EGCG [101].

Taken together, these results appear promising for the anti-inflammatory functions of several bioactive compounds found in tea, including TF3, EGCG, GCG, GA, teasaponin, oolong extract and L-theanine. However, the quantity and consistency of data remains insufficient to make conclusive claims on the viability of these compounds as anti-inflammatory agents in humans. However, even incremental improvements to chronic inflammatory states may be helpful in treating depression, as inflammation reverberates through to multiple downstream targets, including HPA activity and serotonergic neurotransmission.

\subsection{Restoration of Monoaminergic Systems}

The monoamine hypothesis posits that depression results from dysregulated neurotransmission of one of more monoamines, including serotonin (5-HT), norepinephrine (NE) and dopamine (DA). This theory has been criticized as reductionist [106], and insufficient in considering the upstream factors that induce abnormal monoamine neurotransmission, such as chronic stress and inflammation. Despite the validity of these criticisms, the most common and effective current pharmacological approaches to treating MDD are monoamine reuptake inhibitors, such as selective serotonin reuptake inhibitors (SSRIs) or norepinephrine-dopamine reuptake inhibitors (NDRIs) [11], which function to increase circulating monoamine levels through the inhibition of their reuptake. These medications have been reported to be effective in preventing relapse of MDD in some cases, although data suggest that they are less effective as an isolated treatment than when used alongside other approaches, such as cognitive behavioral therapy [107]. While shortcomings of the monoamine theory are evident, it does not invalidate the notion that targeting monoaminergic systems is one sensible tactic in combating MDD.

As discussed in the previous section, inflammation significantly reduces circulating 5-HT levels, and individuals with MDD are likely to be found with dampened serotonergic systems. It was found that denervation of serotonergic projections reduced the generation of granule cells in the dentate gyrus of the hippocampi of rats, and these effects were reversed by stimulating 5-HT1A receptors or by boosting activity in 5-HT fibers, suggesting the close interconnection between serotonergic systems and hippocampal neuronal health [108] (Figure 3). Additionally, the mesolimbic pathway, consisting of dopaminergic neurons originating in the ventral tegmental area and projecting to the nucleus accumbens, amygdala and hippocampus, mediates motivation and the reward pathway. Numerous data have implicated altered dopaminergic neurotransmission within the mesolimbic pathway in the neuropathology of depression [109]. Norepinephrine (NE) is released together with cortisol from the adrenal gland following stimulation by ACTH. As with cortisol, NE can become chronically elevated under circumstances of constant perceived stress, driving the release of cytokines, which can exert reciprocal effects on the HPA axis [23]. 


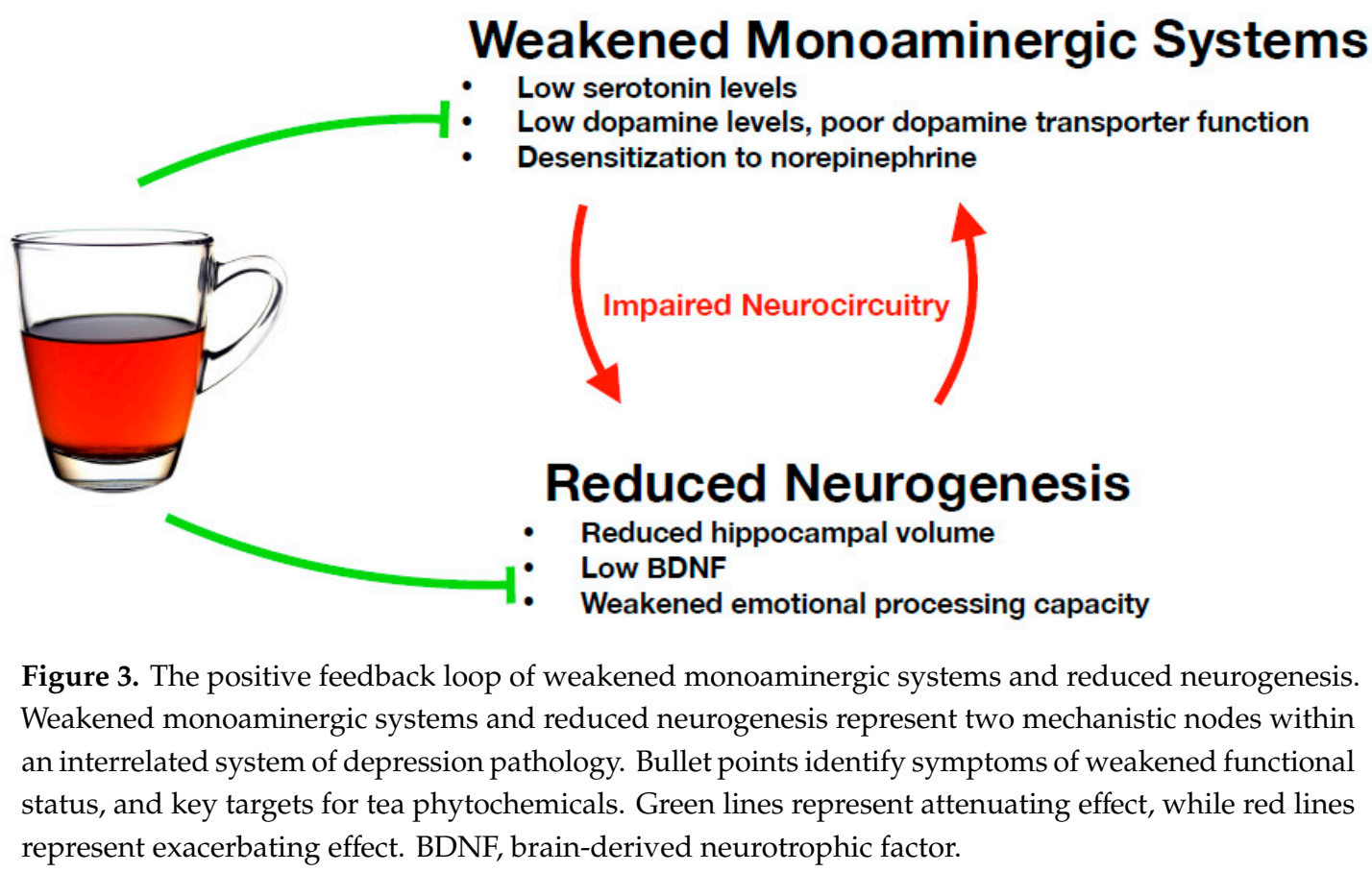

Finally, there exists interconnectivity among 5-HT, DA and NE, wherein any action on one system has the potential to reverberate through to the other systems [110]. For example, DA can inhibit the release of NE from the locus ceruleus. NE can have excitatory and inhibitory effects on DA release in the ventral tegmental area through stimulation of $\alpha-1$ and $\alpha-2$ receptors, respectively [23]. Likewise, both NE and DA can act on $\alpha-1$ and D-2 receptors, respectively, to increase 5-HT release from the dorsal raphe nucleus. As more recent data show, these monoaminergic systems show the potential to be modulated by microbiota species in the intestines, characterizing a relationship known as the gut-brain axis. Taken together, these data indicate that restoration of monoaminergic systems represents an important and interconnected node within the larger network of MDD pathology. Reviewed here are studies that measured how compounds in tea interact directly with monoaminergic systems, and indirectly through their modulations of GM, including mechanistic explanations for the observed effects (summarized in Table 3). 
Table 3. Various tea compounds and their effects on monoaminergic systems.

\begin{tabular}{cc}
\hline Tea Compound & Effect on Monoaminergic Systems \\
\hline L-Theanine & $\begin{array}{c}\text { Increased levels of 5-HT, NE and DA in the PFC, NAC, and HIP. Increased levels of 5-HT } \\
\text { and DA in the ST. Increased DA levels in the HIP [111]. Promoted DA transmission in } \\
\text { HIP via DA D1/5 receptor-PKA pathway activation in AD mouse model [112] }\end{array}$ \\
\hline Green tea & $\begin{array}{c}\text { Administration for 5 weeks, tone of 5-HT was normalized, reduced stress response [113]. } \\
\text { Epicatechin }\end{array}$ \\
$\begin{array}{c}\text { Functioned as anxiolytic in OF and EPM via decreased expression of MAO-A in cortex, } \\
\text { and increased pro-BDNF and BDNF via Akt pathway [114]. }\end{array}$ \\
$\begin{array}{c}\text { Reversed CUMS-induced reduction in 5-HT and NE in the HIP, PFC [115]. Partial } \\
\text { restoration of normal DA and 5-HT following stress-induced neural injury [35]. Null } \\
\text { effect on human GM in 12-week RCT [116]. BTP supplementation more than doubled } \\
\text { butyric acid levels. Significant increases were observed for GTP, but to a lesser extent } \\
\text { than BTP. Increases in SCFA upregulated AMPK activation by 70\% and 289\% for GTP } \\
\text { and BTP, respectively [117]. }\end{array}$ \\
\hline
\end{tabular}

\begin{tabular}{|c|c|}
\hline EGCG & $\begin{array}{l}\text { Partial restoration of normal DA and 5-HT following stress-induced neural injury [35]. } \\
\text { Promoted growth of Bifidobacterium spp. and Lactobacillus/Enterococcus groups, induced } \\
\text { higher concentrations of SCFA when incubated with human GM [118]. Enhanced } \\
\text { adhesion of certain Lactobacillus strains to human epithelial intestinal lines [119]. }\end{array}$ \\
\hline Theaflavins & $\begin{array}{l}\text { Increased DA turnover in FC, as measured by increased DOPAC and DOPAC/DA } \\
\text { ratio [120]. Reduced oxidative stress, preserved DA levels in ST via and protection of } \\
\text { dopaminergic neurons against degeneration by MPTP, improving motor behavior and } \\
\text { expression of DAT and VMAT2 in ST and substantia nigra [121]. }\end{array}$ \\
\hline Catechin & $\begin{array}{l}\text { Significantly increased Bifidobacterium spp. following in vitro incubation with human } \\
\text { fecal samples [122]. }\end{array}$ \\
\hline EGCG3"Me & $\begin{array}{l}\text { Significantly increased Bifidobacterium spp. and SCFA-generating GM species in vivo in } \\
\text { mouse model [123]. Promoted growth of Bifidobacterium spp. and } \\
\text { Lactobacillus/Enterococcus groups, induced higher concentrations of SCFA when incubated } \\
\text { with human GM [118]. }\end{array}$ \\
\hline Gallocatechin gallate & $\begin{array}{l}\text { Promoted growth of Bifidobacterium spp. and Lactobacillus/Enterococcus groups, induced } \\
\text { higher concentrations of SCFA when incubated with human GM [118]. }\end{array}$ \\
\hline Epigallocatechin & $\begin{array}{l}\text { Enhanced adhesion of certain Lactobacillus strains to human epithelial intestinal } \\
\text { lines [119]. }\end{array}$ \\
\hline \multicolumn{2}{|c|}{$\begin{array}{l}\text { BTP, black tea polyphenol mixture; GTP, green tea polyphenol mixture; EGCG, epigallocatechin gallate; EGCG3"Me, } \\
\text { O-Methylated EGCG; 5-HT, serotonin; NE, norepinephrine; DA, dopamine; PFC, prefrontal cortex; FC, frontal } \\
\text { cortex; NAC, nucleus accumbens; HIP, hippocampus; PKA; AD, Alzheimer's disease; OF, open field; EPM, elevated } \\
\text { plus maze; MAO, monoamine oxidase; Akt, protein kinase B; CUMS, chronic unpredictable mild stress; SCFA, } \\
\text { short-chain fatty acids; AMPK, 5'adenosylmonophosphate-activated protein kinase; GM, gut microbiota; DOPAC, } \\
\text { 3,4-dihydroxyphenylacetic acid; DAT, dopamine transporter; VMAT2, vesicular monoamine transporter 2; MPTP, } \\
\text { 1-methyl-4-phenyl-1,2,3,6-tetrahydropyridine. }\end{array}$} \\
\hline
\end{tabular}

A recent study measured the effect of L-theanine $(2 \mathrm{mg} / \mathrm{kg})$ on 5-HT, NE and DA levels in an animal model of depression [111]. Measurements were taken in the limbic-cortical-striatal-pallidal-thalamic (LCSPT) circuit, which included the prefrontal cortex (PFC), nucleus accumbens (NAC), striatum (ST), amygdala, and hippocampus (HIP). The LCSPT circuit was chosen for this study as multiple previous studies showed that depressive symptoms can derive from dysfunctional monoamine neurotransmission relating to LCSPT circuitry [124,125]. L-theanine ameliorated depressive-like behaviors in a chronic unpredictable mild stress (CUMS) rat model, which is a validated rodent model widely used for analyzing mechanisms underlying depression [126]. In the PFC, NAC, and HIP, L-theanine administration significantly increased the levels of 5-HT, NE, and DA. In the ST, the levels of 5-HT and DA were significantly increased following theanine supplementation. In the HIP, only DA levels significantly changed after theanine treatment. Despite the notable results, the authors were unable to identify the detailed signaling pathways responsible for the observed theanine-mediated improvements in monoamine neurotransmission [111].

Zhu et al. [112] found that, in an Alzheimer's Disease (AD) mouse model, supplementation with L-theanine promoted hippocampal dopamine and noradrenaline release, and that these effects were blocked by antagonists of the dopamine D1/5 receptor, suggesting that theanine improved hippocampal monoamine transmission via dopamine D1/5 receptor-PKA pathway activation. This proposed 
mechanism could potentially explain why DA was found to be the only monoamine upregulated in the hippocampus following L-theanine supplementation in the aforementioned study by Shen et al. [111].

Rats that had been administered green tea for five weeks prior to a single restrained stress were found to be more capable of coping with the stressful conditions/stimuli than rats who had not been administered green tea prior to the stressful condition. Stress-induced anxiogenic effects were attenuated and tone of 5-HT was normalized in green tea-treated rats, suggesting that altered 5-HT metabolism allowed rats to cope with stress more effectively [113].

Four milligrams per day of epicatechin in the water of C57BL/6 mice reduced anxiety in the open field (OF) and elevated plus maze (EPM), which was reflected by downregulated cortical monoamine oxidase (MAO)-A levels, but not MAO-B, and increased BDNF levels in the hippocampus but not the cortex. Additionally, EC significantly increased hippocampal and cortical levels of tyrosine hydroxylase (TH), a critical enzyme for monoamine synthesis [114]. EC ingestion did not facilitate neurogenesis in the dentate gyrus, suggesting a non-neurogenic mechanism. Interestingly, this study found that BDNF up-regulation resulted from increased levels of protein kinase B (Akt), rather than ERK/CREB signaling. The measured anxiolytic effect resulting from EC intake was thus interpreted to have resulted from concurrent modulation of complimentary neurotrophic and monoaminergic signaling pathways.

Using the CUMS-induced depression model in mice for five consecutive weeks, tea polyphenols (TP) were administered at a daily dose of $25 \mathrm{mg} / \mathrm{kg}$ or $50 \mathrm{mg} / \mathrm{kg}$ by gavage for three consecutive weeks starting from the third week [115]. The results show that CUMS-induced depression significantly decreased 5-HT and NE in the hippocampus and PFC, and TP administration effectively reversed the alterations in concentrations of 5-HT and NE, in turn exhibiting significant anti-depressant effects in mice with CUMS-induced depression. Zhao et al. [35] also found that administration of either EGCG or GTP were associated with partial restoration of normal DA and 5-HT levels in mice following a four-week restraint stress-induced neural injury. Although reduction in stress-induced neural injuries were attributed to restoration of the ERK1/2 signaling pathway, it is unclear which mechanism mediated TP-induced improvements to monoaminergic systems in either of these studies.

Black tea TF exerted an anxiolytic effect in mice by increasing DA turnover in the frontal cortex, as measured by increased levels of 3,4-dihydroxyphenylacetic acid (DOPAC) and the ratios of DOPAC/DA. These results suggest that TF may be able to induce anxiolytic effects via activation of the dopaminergic system in the frontal cortex [120]. As the following study suggests, TF-induced improvements to DA neurotransmission may be mediated through reduction in free radical damage to these systems, and corresponding improvements in DA transporter function.

A mouse model measured the protective effects of black tea TF on monoamine transporters and behavioral abnormalities in 1-methyl-4-phenyl-1,2,3,6-tetrahydropyridine (MPTP)-induced neurodegeneration [121]. MPTP-injection has been shown to enhance lipid peroxidation in striatum via enzymatic conversion of MPTP to MPP+, inducing the generation of free radicals [127]. Administration of MPTP (30 mg/kg bw for four consecutive days) led to reduced behavior patterns (open field, rotarod and hang test), and reduced expressions of dopamine transporter (DAT) and vesicular monoamine transporter 2 (VMAT2). TF supplementation included $10 \mathrm{mg} / \mathrm{kg}$ orally for three days, followed by the same dose taken $1 \mathrm{~h}$ before intra peritoneal injection of MPTP for four days, totaling a seven-day experimental period. Pre-treatment with TF significantly reduced oxidative stress and preserved striatal DA levels by preventing the degeneration of dopaminergic neurons by MPTP, which resulted in improved motor behavior and improved expression of DAT and VMAT2 in striatum and substantia nigra. These data may highlight the importance of free radical scavenging in mediating the protective effects of tea polyphenols within multiple mechanistic pathways simultaneously. In other words, the anti-oxidant capacities of tea polyphenols may represent at least some portion of the net benefit of tea consumption conferred to both inflammation reduction and restoration of monoaminergic systems. 


\subsubsection{Monoamine Oxidase Inhibition}

Although circulating monoamine levels have been found to improve following tea intake, the data implicating the role of monoamine oxidase (MAO) inhibition as a pathway for these modulations have been inconsistent. Two isoenzymes of MAO have been found in humans, including MAO-A, mainly responsible for the breakdown of 5-HT and NE, and MAO-B, which has relative affinity for DA metabolism [128]. Inhibition of this class of enzymes by various drugs and plant compounds arrests the breakdown of neurotransmitters, increases their concentration in the brain and can bring about antidepressant effects in individuals with MDD $[129,130]$.

One in vitro study showed that none of the common green tea catechins, i.e., EC, EGC, EGC, and EGCG, possess inhibitory effects on MAO-A activity in mouse brain mitochondria [131]. However, an in vivo mouse model showed that four weeks of oral EC supplementation was able to decrease MAO-A expression, but no effect was found on MAO-B [114]. However, MAO-B has been shown to be inhibited to various degrees by several types of black tea and green tea in vitro [132], and EGCG has been shown to inhibit MAO-B in brains of rats [133]. Despite the contradictory data, there is a general consensus among the aforementioned studies, and others [134,135], that tea polyphenols can at best confer modest decreases in MAO activity, however this marginal effect is likely insufficient to consider it a primary mechanism driving the observed attenuations to monoaminergic systems following tea intake. However, more research is needed to examine the impact of various tea compounds and combinations of tea compounds on the in vivo attenuation of MAOs, particularly MAO-A, due to stronger association of that isoenzyme with depression and other mood disorders [130].

\subsubsection{Modulating Monoamines via the Gut-Brain Axis}

The gut-brain axis is a bi-directional communication network connecting the central nervous system (CNS), to the enteric nervous system (ENS) [136]. A complex reflexive network of efferent fibers projecting into the gastrointestinal (GI) tract and afferent fibers that project into a number of interconnected regions of the CNS facilitate communication within the axis [137]. Within this network, changes in gut microbiota can trigger changes in brain chemistry, including neurotransmitter levels [138]. Absence and/or modification of the gut microbiota (GM) in mice affects the HPA axis response to stress $[139,140]$ and anxiety behavior $[141,142]$. For example, germ free (GF) mice, i.e. mice that were born and bred in entirely germ-free environments, had significantly lower 5-HT levels and overall 5-HT receptor expression in the amygdala and hippocampus than mice that were raised in a probiotic environment [143-145]. Tea polyphenols and aromatic tea compounds have been shown to be capable of exerting profound effects in the gut by inducing growth of GM strains, or "psychobiotics", that modulate the gut-brain axis in beneficial ways to mental health and depression [146-148].

Tea polyphenol intake ( $400 \mathrm{mg} /$ volunteer, three times per day, for four weeks) increased Bifidobacterium spp. (the acid forming bacteria) in total counts in a human trial [149]. It should be noted that this study is from 1992, and recent estimates place the tolerable upper-intake level of tea polyphenols around $400 \mathrm{mg}$ per day [150]. More recently, $4 \%$ green tea powder supplementation for 22 weeks in HFD mice significantly increased Lactobacillus species, in both number and diversity [151]. After incubation with human fecal samples, (+)-Catechin (150 mg/L exposure) in vitro lead to increases in both Lactobacillus spp. and Bifidobacterium spp., although increases only achieved significance for the latter [122].

Bifidobacterium spp. have been associated with beneficial psychobiotic effects, including Bifidobacterium longum 1714, shown to have effectively attenuated cortisol output, daily reported stress levels, and subjective anxiety in response to the socially evaluated cold pressor test in healthy human volunteers $(n=22)$ [152]. Another Bifidobacterium strain, Bifidobacterium infantis, reversed HPA axis hyperactivity in GF mice as measured by plasma ACTH and corticosterone in response to restraint stress [139]. It was found that supplementation with O-Methylated EGCG (EGCG3"Me) isolated from oolong tea leads to significant increases in Bifidobacterium compared to mice not treated with EGCG3"Me, suggesting a modulatory effect of EGCG3"Me on Bifidobacterium spp [123]. An 
earlier study by the same authors showed that EGCG, GCG, and EGCG3"Me isolated from Chinese oolong tea promoted the growth of Bifidobacterium spp. and Lactobacillus/Enterococcus groups when incubated with human intestinal microbiota in vitro [118]. A preparation of $100 \mathrm{mg}$ of mixed tea catechins (approximate to a cup of green tea) three times daily for three weeks induced a significant increase in Lactobacillus species in broiler chickens [153].

Enterococcus species have been shown to generate 5-HT [142], while GABA can be secreted by both Lactobacillus and Bifidobacterium strains [154]. Bravo et al. [155] demonstrated that chronic administration of probiotic Lactobacillus rhamnosus improved GABA receptor expression in cortical regions and the hippocampus, which reduced stress-induced corticosterone and depression behavior. Importantly when the vagus nerve was removed from mice, the neurochemical and behavioral effects were not found, indicating the vagus nerve as a major modulatory communication pathway for psychobiotics. One recent study found that a Lactobacillus strain, Lactobacillus plantarum, was able to reverse reduced DA and 5-HT levels in depressed mice and increase levels of BDNF [156]. These data suggest that tea polyphenol-induced modulations to Lactobacillus, Bifidobacterium, and Enterococcus species may be able to explain some of the improvements to monoaminergic systems, HPA hyperactivity, and BDNF that have been observed following tea intake.

A mechanism by which tea polyphenols may be functioning to increase the levels of probiotic strains such as Bifidobacterium or Lactobacillus may be by improving their adhesion to intestinal mucosa, which is considered as a prerequisite for colonization and an important characteristic when measuring the ability of probiotic strains to confer health benefits. Bustos et al. [119] investigated the ability of several tea polyphenols to improve adhesion of Lactobacillus strains to human epithelial intestinal cell lines. Both EGCG and EGC significantly increased adhesion of different Lactobacillus strains to intestinal cells, however some tea polyphenols did not, depending on Lactobacillus strains, and the epithelial cell lines tested in the study.

Tea polyphenols have shown variable effects on Bacteroides, another potentially psychobiotic species whose abundance was shown to negatively correlate with brain signatures associated with depression [157]. EGCG, GCG and EGCG3"Me cultured with human intestinal GM in vitro were found to inhibit the growth of Bacteroides [118]. Another study found that EGCG3"Me inhibited growth of Bacteroides in HFD mice between Weeks 0 and Week 3 of the experiment, but Bacteroides began to proliferate starting from Week 4 of EGCG3"Me supplementation [123]. It is still unclear what the overall effect of polyphenol intake is on Bacteroides species, and equally important, what the overall effect of Bacteroides species is on human health [158]. Bacteroides have been shown to be elevated among individuals with obesity [159], and reduced among individuals that underwent six weeks of exercise training [160], suggesting that Bacteroides can correlate with measures of poor human health, despite their association low brain signatures of depression. The inconsistency in these data may be because Bacteroides are typically more abundant among people with long-term diets rich in animal protein and saturated fats [161], and less abundant among people with plant carbohydrate-based food diets, which remains a poorly understood and highly-contested topic. Taken together, multiple factors need more careful analysis regarding the tea-mediated effects of GM on depression, including which species of GM can serve as realistic modulatory targets for tea polyphenols, and the mechanisms by which those targeted GM species can attenuate MDD pathology.

\subsubsection{Generation of Short-Chain Fatty Acids}

Short-chain fatty acids (SCFAs) are another factor in the tea-gut-brain axis, as they are products of microbial fermentation of undigested carbohydrates in the GI tract, and can increase as a result of tea intake [162]. The three principal SCFAs (butyrate, acetate and propionate) can cross the blood brain barrier $[163,164]$ where they have been shown to alleviate psychosocial stress-induced alterations in behavior, and exhibit antidepressant and anxiolytic effects in mice [165]. One proposed mechanism of procognitive and beneficial behavioral effects of butyrate has been suggested to be through its potent 
inhibition of histone deacetylases (HDACs), promoting histone acetylation and stimulation of gene expression in host cells [166].

In a human trial, high doses of tea polyphenol intake $(400 \mathrm{mg} /$ volunteer, three times per day, for four weeks) significantly increased levels of acetic and propionic acids [149]. A study researching the in vivo effects of tea polyphenol supplementation in HFD mice reported that butyric acid more than doubled after black tea polyphenol (BTP) supplementation compared to the control group [117]. Black tea in particular, more so than green tea, has been shown to be highly effective in generating colonic SCFA due to the high molecular weight of black tea polyphenols, which generally remain undigested until they reach the colon and interact with GM [162]. Additionally, Henning et al. [117] showed that SCFA generation by both green tea and black tea polyphenols induced a significant increase in hepatic 5'adenosylmonophosphate-activated protein kinase (AMPK), by $70 \%$ and $289 \%$ for green and black tea, respectively. We previously characterized the chain of mechanisms by which oxidized polyphenols may be more effective promoters of AMPK than unoxidized polyphenols, through relatively strong inhibition of carbohydrate digestive enzymes, $\alpha$-glucosidase and $\alpha$-amylase, which creates more substrate for SCFA generating interactions in the colon, leading to greater AMPK activation [162]. AMPK activation was recently shown to ameliorate depressive-like behaviors in mice by elevating hippocampal neurogenesis potentially via PKC zeta/NF- $\mathrm{KB} / \mathrm{BDNF} / \mathrm{TrkB} / \mathrm{CREB}$ signaling in neurons [167].

In a HFD mouse model, EGCG3"Me significantly increased butyrate-producing bacteria such as Eubacterium, Ruminococcaceae (including Faecalibacterium) and Roseburia, and the majority of acetate-producing bacteria such as Coprococcus and Bifidobacterium [123]. Zhang et al. [118] showed that EGCG, GCG and EGCG3"Me were able to induce higher concentrations of SCFA compared to control within a human fecal incubation experiment. Taken together, SCFA represents an interesting piece of the gut-brain axis that may have relevance to the antidepressant activity in tea. However human trials are necessary given the vast differences between human and mouse GM, and great inter-individual variability among human GM.

\subsection{Restoring Neurogenesis and Neuroplasticity}

As mentioned above, chronic stress and inflammation lead to hypercortisolemia, or chronic elevated cortisol levels with neurotoxic effects, leading to reduced neurogenesis, as seen in neuroimaging studies showing reduced volume in the prefrontal cortex (PFC), especially in the subgenual PFC, basal ganglia and hippocampus of patients with MDD [168,169]. Additionally, natural age-related stress in the brain [170-172], or environmentally imposed stressors such as air pollution [173] can cause oxidative damage to neurons [174] and reduce their functionality, a process that has been linked to depression in meta-analyses [175]. The regions of the brain including the amygdala, hippocampus, basal ganglia, and nucleus accumbens are responsible for mediating raw, unprocessed emotion, while areas of the PFC mediate cognitive processing of emotions [176]. With reduced volume and interconnectivity among these critical emotion-processing centers, individuals become less capable of executive function and mood regulation, a proposed pathophysiology of depression [177]. Meta-analyses of human neuroimaging studies showed that patients with MDD had increased activation of the interior cingulate and amygdala and decreased activation of striatum and dorsolateral PFC, which presented as hyperactivation for negative stimuli and hypoactivation for positive stimuli [178]. The impeded ability to process emotion properly causes an individual to feel more overwhelmed, respond more reactively to external stimuli, all of which further fuel the cycle of chronic stress/inflammation. For these reasons, fighting the stress-induced reduction in neurogenesis has been said to be critical to the efficacy of antidepressant treatment [179].

Brain-derived neurotrophic factor (BDNF) is a neurotrophin that promotes the survival of existing neurons and encourages the growth and differentiation of new neurons and synapses [180]. It was found that serum levels of BDNF are reduced in patients diagnosed with MDD [181] and that depressive behavior could be induced in rats following a knock-out experiment of BDNF in the dorsal dentate 
gyrus [182]. BDNF has been shown to protect against stress-induced neuronal damage [183] and affect hippocampal neurogenesis [184], which has led some to suggest that BDNF may be an important agent for therapeutic recovery from MDD [185-187]. Conceptually, the role of BDNF and neurogenesis in treating MDD is to help the brain return to a state of juvenile-like plasticity by encouraging the growth of new neurons and synapses that can be utilized to establish new pathways for emotional processing which mitigate stress and encourage healthy cognitive behavior. Here, we review studies that have measured how compounds in tea have been observed to interact with neurons to affect BDNF or neuroplasticity, including the proposed mechanisms for those effects (summarized in Table 4).

Table 4. Various tea compounds and their effects on BDNF, neurogenesis and neuroplasticity.

\begin{tabular}{cc}
\hline Tea Compound & Effect on Neurogenesis/Neuroplasticity \\
\hline Teasaponin & $\begin{array}{c}\text { Six-week supplementation in HFD model attenuated BDNF deficits in the HIP, prevented } \\
\text { recognition memory impairment [105]. }\end{array}$ \\
\hline L-theanine & $\begin{array}{c}\text { Increased exploratory activity in OFT, enhanced object recognition memory, significantly } \\
\text { increased BDNF levels and BrdU-, Ki67, and DCX-labeled cells in the granule cell layer [188]. }\end{array}$ \\
\hline & $\begin{array}{c}\text { DCX-positive neurons showed more elaborate dendritic trees, accompanied by significantly } \\
\text { increased HIP neurogenesis [189]. Attenuated HFFD-induced neuronal damage, reduced } \\
\text { cognitive disorder via upregulation of CREB/BDNF pathway [95]. Submicromolar } \\
\text { concentrations potentiated the neuritogenic ability of BDNF in PC12 cells [190]. Attenuated } \\
\text { corticosterone-induced cytotoxicity, up-regulated Shh pathway [191]. Induced SH-SY5Y cell } \\
\text { growth in vitro [192]. RT-PCR showed enhanced BDNF and TrkB mRNA levels, activated Akt } \\
\text { and CREB/BDNF pathways, inhibited sevoflurane-induced neurodegeneration, improved } \\
\text { learning and memory retention [193]. Targeted BDNF and proBDNF signaling pathways, } \\
\text { normalized tat-mediated increases in proapoptotic proBDNF, normalized tat-mediated } \\
\text { decreases in mature BDNF protein in hippocampal neurons [194]. Following spinal cord injury } \\
\text { in rats, increased expression of BDNF, GDNF, improved locomotor recovery [195]. }\end{array}$ \\
\hline EgCG & $\begin{array}{c}\text { Enhanced the neurogenic properties of EGCG [190]. Primary EGC metabolite, EGC-M5, and } \\
\text { several conjugated forms improved neurite length and neurite number in SH-SY5Y cells [196]. }\end{array}$ \\
\hline Epicatechin & $\begin{array}{c}\text { Enhanced the neurogenic properties of EGCG [190]. Targeted BDNF and proBDNF signaling } \\
\text { pathways, normalized tat-mediated increases in proapoptotic proBDNF, normalized } \\
\text { tat-mediated decreases in mature BDNF protein in hippocampal neurons [194]. }\end{array}$ \\
\hline Non-EGCG GTP & $\begin{array}{c}\text { Plastic changes in dendritic arborizations of dentate granule cells, improved spatial learning in } \\
\text { Morris water maze [197]. }\end{array}$ \\
\hline Gallic acid & $\begin{array}{c}\text { Ameliorated TMT-induced anxiety and depression, improved cell densities in the CA1, CA2, } \\
\text { CA3 and DG hippocampal subdivisions [198]. }\end{array}$ \\
\hline
\end{tabular}

HFD, high-fat diet; BDNF, brain-derived neurotrophic factor; HIP, hippocampus; OFT, open-field test; BrdU, 5-Bromo-2'-deoxyuridine; DCX, doublecortin; HFFD, high-fat/high-fructose; Shh, Sonic hedgehog; CREB, cyclic AMP response element binding protein; RT-PCR, reverse transcription polymerase chain reaction; TrkB, tropomyosin receptor kinase B; Akt, protein kinase B; GDNF, glial cell line-derived neurotrophic factor; EGCG, epigallocatechin gallate; GTP, green tea polyphenol mixture.

Eight weeks of high-fat diet (HFD) in C57BL/6J mice followed by treatment with oral teasaponin $(0.5 \%)$ mixed in HFD for another six weeks effectively prevented HFD-induced recognition memory impairment, and improved neuroinflammation and BDNF deficits in the hippocampus, in addition to attenuating gut microbiota alterations [105].

Compared to a control group, newborn rats fed water containing $0.3 \%$ theanine for six weeks showed increased exploratory activity in the open-field test with enhanced object recognition memory, and significantly increased BDNF levels accompanied by significantly increased number of BrdU-, Ki67-, and doublecortin (DCX)-labeled cells in the granule cell layer, suggesting that theanine administration facilitated neurogenesis and improved plasticity in the developing hippocampus [188]. In corroboration with these results, DCX-positive neurons showed more elaborate dendritic trees, accompanied by significantly increased hippocampal neurogenesis following $2.5 \mathrm{mg} / \mathrm{kg}$ EGCG treatment in mice. BDNF was not measured in this study [189].

Three-month-old C57BL/6J mice were fed a high-fat/high-fructose diet (HFFD), which induced peripheral inflammation and neuronal loss/damage [95]. EGCG supplementation (2 g/L), in drinking water) attenuated HFFD-induced neuronal damage and reduced cognitive disorder by significantly up-regulating the ERK/CREB/BDNF signaling pathway. This study may provide compelling evidence 
that EGCG can restore HFFD-induced hippocampal changes and reverse neuronal damage via significant upregulation of the ERK/CREB/BDNF signaling pathway [95].

Gundimeda et al. [190] showed that in PC12 cells treated in vitro with even submicromolar concentrations of EGCG $(<0.5 \mu \mathrm{M})$ potentiated the neuritogenic ability of a low concentration $(2 \mathrm{ng} / \mathrm{mL})$ of BDNF. Furthermore, it was observed that, while EGC and EC were unable to significantly potentiate the neuritogenic ability of BDNF individually, both catechins enhanced the BDNF potentiating capacity action of EGCG.

A recent study used adrenal phaeochromocytoma PC12 cell line to study the neuronal damage induced by corticosterone in vitro, which is a common in vitro experimental model of depression-induced neuronal damage $[191,199]$. Results showed that exposure to high concentrations of corticosterone induced cytotoxicity and downregulated the Sonic hedgehog pathway (Shh) in PC12 cells, and that these effects were attenuated by administration of EGCG. Interestingly, this study found the optimal concentration of EGCG for attenuating the corticosterone-induced decreases in PC12 cell viability to be $20 \mu \mathrm{M}$, however Pervin et al. [192] found the optimal concentration of EGCG for SH-SY5Y cell growth in vitro to be $0.05 \mu \mathrm{M}$, with diminishing effects at higher concentrations. Similarly, Gundimeda et al. [190] showed that EGCG was able to induce BDNF-mediated neuritogenic growth at submicromolar concentrations $(<0.5 \mu \mathrm{M})$. Inconsistencies in data may be due to the use of PC12 rodent cell lines in one study, and human-derived SH-SY5Y cell lines in the other. Additionally, these studies examined the activation of different pathways, one measuring the Shh pathway and another measuring a BDNF pathway. Thus, these inconsistencies highlight that that optimally efficacious level of tea intake may vary considerably depending on which mechanistic pathway, in addition to which animal species, the tea compounds are functioning within.

Interestingly, we found one study that showed negative results for the ability of EGCG to induce neurogenesis in mice [200]. This study used a dosage of EGCG that was an order of magnitude higher than the dosages used in the other experiments reviewed here $(\sim 250 \mathrm{mg} / \mathrm{kg} /$ day $)$, which in a $70 \mathrm{~kg}$ human translates to a dose of $1422 \mathrm{mg}$ EGCG [201], or over double the estimated toxic dose $(600 \mathrm{mg})$ and four-fold standard estimates for acceptable daily intake (300-400 mg/day) [150]. The finding that this large dosage was ineffective at inducing neurogenesis in mice lends support to the research by Pervin et al. [192,202] who measured a diminishing ability of EGCG to induce cell growth at high doses.

To measure the effects of non-EGCG tea catechins on age-related changes in rat hippocampal formation (HF) and behavioral alterations, Rodrigues et al. [197] prepared a green tea extract (GTE) rich in catechins and poor in EGCG. GTE-treated mice presented plastic changes in dendritic arborizations of dentate granule cells accompanied by improved spatial learning in the Morris water maze, demonstrating that non-EGCG catechins protected HF from aging-related declines in structural formation with repercussions on behavioral performance.

Unno et al. [196] showed the primary EGC metabolite, EGC-M5, and several of its conjugated forms, led to improvements in human neuroblastoma SH-SY5Y cells, where neurite length was significantly prolonged by EGC-M5, and the number of neurites was increased significantly by all metabolites examined [196]. This study also examined in vitro BBB permeability of EGCG, finding that EGCG and the combination of EGCG's hydrolysis products, EGC and gallic acid (GA), can pass through BBB and effectively induce neurite growth. The combination of EGC and GA worked more efficiently than either one alone. This finding suggests that ingestion of EGCG can provide neurogenic benefits even after undergoing in vivo hydrolysis to EGC and GA.

In corroboration with the reported effects of GA, an in vivo mouse model found that GA ameliorated trimethyltin chloride (TMT)-induced anxiety and depression in behavioral tests, and that cell densities in the CA1, CA2, CA3 and DG hippocampal subdivisions from GA-treated rats were higher than in saline treated rats [198]. Several additional in vivo mouse models have found EGCG or the combined effect of green tea catechins to significantly upregulate BDNF expression, resulting in neurogenic effects in hippocampal neurons [193-195,203]. 
Taken together, these data suggest that even small doses of teasaponin, L-theanine, gallic acid, and both EGCG and non-EGCG tea catechins can exert neurogenic effects, at least in mice and in vitro models. An important finding is that that there appears to be an optimal dosage for EGCG-induced neurite outgrowth, and excessive intake of EGCG may hinder the ability of EGCG to promote neurogenesis. These findings are encouraging for the potential viability of neurogenic mechanisms to mediate antidepressant effects of tea consumption. However, more data are needed to examine the mechanisms involved and dosages necessary to optimize tea-induced neurogenesis.

\subsection{Mood Enhancement}

It may be that, for some people, the very activities of preparing and consuming tea bring about mood-enhancing effects that are separate from and additional to the physiological effects within the four nodal systems discussed above. For those who derive pleasure from the taste, aroma, aesthetics, or the moment of time taken away from a busy routine to stop and consume tea, there may be improvements to affective state that confer anti-depressive effects by their own right. It has been shown that positive affective states build enduring personal and cognitive resources [204] and higher levels of creativity compared to neutral mood states in meta-data from mood-creativity research [205]. Furthermore, mood may impact not only cognitive control processes, but also attention, perception, and memory [206-208]. Likewise, neuroimaging data suggest that a reciprocal relationship may exist, in which mood affects cognition, but cognition also affects mood [209], and that components of this neural network are predictive of response efficacy to MDD treatment [210].

In a clinical trial, greater reported happiness throughout the day was associated with lower salivary cortisol on both working and nonworking days, reduced fibrinogen stress responses, and lower ambulatory heart rate in men [211]. Positive mood induction significantly decreased psychological distress and emotional processing deficits compared with a neutral mood induction condition in a trial studying depressed stroke subjects $(\mathrm{n}=30)$ and rheumatic/orthopedic controls $(n=30$ [212]. These data suggest that small daily inductions of positive affect, creativity and overall cognition may effectively accumulate over time and contribute to long-term protective effects against MDD. Here, we review studies that have measured effects on positive affect resulting from tea consumption, including mechanistic explanations for the observed effects.

At the meta-data level, tea intake has not been strongly associated with improved affective state, with the exception of improved alertness [213,214], likely resulting from synergistic effects of caffeine and L-theanine [215]. One randomized, placebo-controlled, single-blind study $(n=23)$ conducted in four sessions found that $4 \mathrm{~g}$ of matcha tea powder induced no significant changes in mood, but did induce significant improvements in attention tasks and psychomotor speed in response to stimuli [216]. In two studies measuring the effect of EGCG on affective state, one reported no mood effect in response to $270 \mathrm{mg}$ EGCG tablets [217], and another found $300 \mathrm{mg}$ EGCG supplementation to significantly increase self-rated calmness $(p=0.04)$ and reduced stress $(p=0.017)$ measured as change-from-baseline [218].

Einother et al. [219] showed that a regular tea consumer preparing and drinking a single cup of tea experienced significant feelings of pleasure. However, Einother et al. [220] later measured the pleasurable effects of the same quantity of tea, and found no effect on pleasure. Notably, the differences between the first and second studies were twofold; participants in the first study were regular tea drinkers, and also they were involved in the preparation of the tea they consumed. Participants determined their own steep-time, addition of milk/sugar, stirring, etc. These differences in experimental setup are significant, and results are concomitant with data showing that simple preparatory tasks can heighten product involvement and thereby pleasure experienced [221,222]. Being a regular tea consumer was likely an influential factor, considering the importance of anticipatory (appetitive) positive affect state [223], and the neural correlation of desire, wanting, liking, etc. with pleasurable effect of the wanted [224]. While these data suggest that the act of tea consumption will not confer mood-enhancing benefits to everyone, they do suggest that, for individuals who have rituals or 
habits surrounding tea consumption, this activity can be mood-enhancing, and perhaps through that mechanism, anti-depressive.

There are numerous factors modulating the potential change to affective state due to tea consumption. The expectation itself, resulting from having ingested caffeine has been shown to improve mood as well as performance [225]. Physical warmth of holding a warm beverage has been shown to affect social information processing, leading to increased perceived warmness of another person [226] and perceived emotional connection [227], although the connection between physical and emotional warmth has been disputed [228]. Compounds with bitter taste were found to be negatively correlated with mood scores, and there may be potential asymmetry in the effects of bitter and sweet taste modalities on mood [229]. However, the effect size in the mentioned study above was dependent on participants' perception of the compound as bitter, which is a sensitivity with great inter-individual variability based on variations in bitter taste receptor subtypes [230-232], which are differentially expressed throughout the population $[233,234]$ based on multiple factors including age and genetics [235].

Cultural habits may also impact the mood effects conferred by tea consumption. Firstly, Western nations have historically built habits around adding milk and sugar to tea [236], which has been found to mitigate many of the beneficial health effects of tea polyphenols [237,238], likely due to a condensation reaction between the hydroxyl group of the phenolic compounds and the hydroxyl group of the sucrose molecule leading to the formation of a glycoside. Additionally, due to the rich content of bitter polyphenol compounds in tea, and the high-fructose nature of the "Western diet", it is possible that tea may be more easily perceived as bitter to Western drinkers, or other populations that tend to consume sweet foods. However, despite the Western diet, tea consumption remains at strong or increasing popularity in Western nations such as Germany and the United States [239,240].

Taken together, these data suggest that mood-enhancement as an additional mechanism for mediating antidepressant activity may be viable for some individuals, but less viable for others, depending on a large number of variable and subjective factors. It may be an interesting topic for future research to design mood-enhancing, mindfulness-based, or otherwise therapeutic rituals surrounding daily tea consumption, which could function to confer benefits to affective state on top of the number of neurobiological benefits we have discussed.

\subsection{Determining Bioavailability, Pharmacokinetics and Pharmacodynamics}

In 2010, Del Rio et al. [241] discovered that the overall bioavailability of green tea flavan-3-ols was an order of magnitude higher than previous estimations ranging from $2 \%$ to $8.1 \%$ [242,243]. Del Rio found bioavailability averaged $39 \%$ in humans after considering polyphenol metabolites generated from interactions with colonic microbiota [241]. Examining the interactions between polyphenols and the GM is critical to understanding the bioavailability of these compounds in the body, since $90-95 \%$ of dietary polyphenols have been shown to accumulate and break down in the large intestine [244]. Since discovering the importance of GM to polyphenol bioavailability, more research has emerged which seeks to measure the mechanisms by which GM cleave flavonoid conjugates and glycosides, thereby modulating their health effects [245-247]. Shang et al. [248] showed in rats that a single oral administration of EC $(350 \mathrm{mg} / \mathrm{kg})$ underwent in vivo metabolic reactions, including methylation, dehydration, hydrogenation, glucosylation, sulfonation, glucuronidation and ring-cleavage, resulting in 67 metabolites found in urine [248].

Recently, the first in vivo human experiment was conducted using a radiolabeled epicatechin isotope (2-C-14) (EC14) to track flavonoid bioavailability in the human body [249]. Eight male volunteers each ingested a drink containing $207 \mu \mathrm{M}$ radiolabeled EC14, after which blood and urine samples were attained over a 48 -h period. It was found that EC14 was absorbed in the small intestine as 12 structurally-related epicatechin metabolites (SREMs), attaining sub- $\mu \mathrm{M} / \mathrm{L}$ peak plasma concentrations (C-max) around $1 \mathrm{~h}$ after ingestion. SREMs were excreted in urine over a $24 \mathrm{~h}$ period in amounts corresponding to $20 \%$ of EC14 intake. On reaching the colon, EC14 underwent GM-mediated 
conversions yielding the 5C-ring fission metabolites (5C-RFMs), which appear in plasma as phase II metabolites with a C-max of $5.8 \mathrm{~h}$ after intake, and were excreted in quantities equivalent to $42 \%$ of the ingested EC14. Other catabolites excreted in 0-24 h urine amounted to $28 \%$ of intake. Overall EC was found to be highly bioavailable, with urinary excretion indicating that $95 \%$ is absorbed and passes through the circulatory systems as a diversity of phase II metabolites [249]. This study was the first to track flavonoid metabolism in humans with such a high degree of specificity. However, no study has yet tracked these metabolites for in vivo penetrability of a human BBB. For now, only animal models can provide insight into the bioavailability of flavonoid metabolites in the brain.

Wang et al. [250] fed rats with $17 \mathrm{mg} / \mathrm{kg}$ of a grape-derived polyphenolic preparation (GP) comprising proanthocyanidin, catechin and EC to test the effects of their metabolites on neurological disorders [250]. Following acute intake, low, unquantifiable amounts of EC metabolites were detected in rat brains. However, following 10 days of chronic supplementation, plasma metabolite levels increased substantially, and trace amounts of unmetabolized EC and a mixture of EC metabolites were found in the brain at a concentration of $484 \mathrm{nM}$, and potentially could have been higher if ring fission metabolites, which were not analyzed, were also present. Additionally, this study reported that a biosynthetic proanthocyanidin EC metabolite identified in the brain, 3'-O-methyl-epicatechin-5-O-beta-glucuronide (3'-O-Me-EC-Gluc), promoted basal synaptic transmission at physiologically relevant levels in hippocampus slices through mechanisms associated with CREB/BDNF signaling [250]. If these data were taken together with research by Unno et al. [196] showing the ability of the EGC metabolite, EGC-M5, and several of its conjugated forms, to cross a human BBB model, and data from Pervin et al. [192] showing an ideal concentration of $50 \mathrm{nM}$ of EGCG for SH-SY5Y cell proliferation, it would appear at least feasible to hypothesize that in human conjugated polyphenol metabolites can cross the BBB, and accumulate in human brains at levels of physiological relevance to mitigating MDD neuropathology [192,202]. However, a great deal of research is still needed to understand the bioavailability and brain permeability of various tea polyphenols and their metabolites.

\section{Discussion}

While it appears promising that tea consumption can confer mild anti-depressive effects through a number of mechanisms, it remains unclear as to which specific types of tea (i.e., green, white, black, oolong, yellow, and dark) produce maximal net effects on risk reduction of depression. We hypothesize that consuming multiple tea types regularly would confer greater effects than consuming equivalent amounts of only one tea type. For instance, green tea possesses a higher anti-oxidant capacity relative to other teas due to its high total phenolic content [251], however the high molecular weight oxidized tea polyphenols, such as those in oolong and black teas, have shown to be relatively effective promoters of SCFA generation and AMPK activation [162].

Wang et al. [252] tracked the metabolite profiles of an identical batch of fresh leaves that was processed into each of the six major tea types, and the results may provide insight as to the relative capacities of certain tea types to confer anti-depressive effects through different mechanisms [252]. This study found significant differences in the profiles of certain metabolites with considerable relevance to the antidepressant mechanisms discussed in this review. For example, gallic acid (GA) increased in white tea, black tea and dark tea, likely due to "crack reaction" products resulting from fermentation and post-fermentation processing [253,254]. Wang et al. [252] found that white tea processing lead to two-fold increases in tryptophan and GABA, and these amino acids were found mostly to decrease, or only increase marginally, in other tea types. Tryptophan as the serotonin precursor, and high-GABA content tea, shown to alleviate depression and stress in mice $[68,255]$, both may be relevant to added anti-depressive effects conferred by white tea. Following black tea processing, there was a 12.73-fold decrease in EGCG, coinciding with a 30.74-fold increase in theaflavin digallate, which may carry considerable implications for reasons already discussed. An interesting area of future research may be examining the isolated effects of certain tea types within a mechanistic system, and then comparing the 
synergistic effects of two or more tea types within that same system. We may find that diversity in tea is highly beneficial, just as diversity in other forms of dietary intake.

\section{Conclusions}

This article critically examines the biochemical and neurobiological effects of tea consumption vis-à-vis our current understanding of the mechanisms purported to underlie depression. Prior research has documented an inverse relationship between tea consumption and depression. Based on this review, it appears that many biochemical and neurobiological effects of tea mimic anti-depressant processes within our current depression pathology framework.

In summary, there appear to be multiple pathways affected by multiple constituents in tea that can collectively lead to antidepressant effects in tea drinkers. Notable among these pathways is the ERK/CREB/BDNF signaling pathway, which has been shown to be up-regulated by a number of compounds in tea including teasaponin, L-theanine, EGCG, EC and combinations of green tea catechins and their metabolites. Other tea-mediated mechanisms include increased SCFA/AMPK signaling, notably effective in oxidized tea polyphenols, and improved generation of monoamine and BDNF-up-regulating "psychobiotic" bacterial strains in the GM, such as Lactobacillus and Bifidobacterium species. Additionally, reduced inflammation, improved monoaminergic systems, and reduction of stress response via normalized HPA axis activity all represent major nodes of tea-mediated antidepressant activity. However, at this time, there are not enough data to specify which mechanisms are responsible for producing the largest net induction of antidepressant response, which might serve as an interesting topic for future research. This review is the first to use modern integrated theories of depression neurobiology to comprehensively map out the mechanisms through which tea may be working to reduce risk of depression. In conclusion, the current data suggest that daily consumption of moderate amounts of tea may offer significant potential benefit in the risk reduction of depression.

Author Contributions: Conceptualization, formal analysis, investigation, data curation, writing-original draft preparation, writing-review and editing, visualization; D.O.R.; supervision, project administration, funding acquisition, L.Z.; methodology, software, validation, resources, D.O.R. and L.Z.

Funding: This research was funded by the National Key Research \& Development Program, 2018YFD1000601 and Fund of the Technology Innovation of Guizhou Province, $\{2014\} 45$.

Conflicts of Interest: The authors declare no conflict of interest.

\section{Abbreviations}

Major depressive disorder (MDD); hypothalamic-pituitary-adrenal (HPA); risk ratio (RR); confidence interval (CI); corticotropin-releasing hormone (CRH); adrenocorticotropin (ACTH); lipopolysaccharide (LPS); glucocorticoids (CORT); gamma-aminobutyric acid (GABA); blood brain barrier (BBB); green tea polyphenols (GTP); forced swimming tests (FST); tail suspension tests (TST); epigallocatechin gallate (EGCG); epigallocatechin (EGC); autonomic nervous system (ANS); Salivary $\alpha$-amylase (sAA); salivary chromogranin A (CgA); extracellular signal-regulated kinase (ERK); cyclic AMP response element binding protein (CREB); brain-derived neurotrophic factor (BDNF); single prolonged stress (SPS); paraventricular nucleus (PVN); reactive oxygen species (ROS); interleukin (IL); tumor necrosis factor alpha (TNF- $\alpha)$; C-reactive protein (CRP); theaflavin-3, $3^{\prime}$-digallate (TF3); high-fat diet (HFD); green tea extract (GTE); nuclear factor kappa-light-chain-enhancer of activated B cells (NF-kB); high-fat/fructose diet (HFFD); epicatechin (EC); gallic acid (GA); gallocatechin gallate (GCG); monocyte chemoattractant protein-1 (MCP-1); nitric oxide (NO); cyclooxygenase-2 (COX-2); serotonin (5-HT); norepinephrine (NE); and dopamine (DA); limbic-cortical-stratial-pallidal-thalamic (LCSPT); prefrontal cortex (PFC); nucleus accumbens (NAC); striatum (ST); hippocampus (HIP); chronic unpredictable mild stress (CUMS); Alzheimer's Disease (AD); open field (OF); elevated plus maze (EPM); tea polyphenols (TP); theaflavins (TF); 3,4-dihydroxyphenylacetic acid (DOPAC); dopamine transporter (DAT); vesicular monoamine transporter 2 (VMAT2); monoamine oxidase (MAO); germ free (GF); central nervous system (CNS); enteric nervous system (ENS); gastrointestinal (GI); gut microbiota (GM); O-Methylated EGCG (EGCG3"Me); Short-chain fatty acid (SCFA); 5'adenosylmonophosphate-activated protein kinase (AMPK).

\section{References}

1. Sinyor, M.; Rezmovitz, J.; Zaretsky, A. Screen all for depression. Br. Med. J. 2016, 352. [CrossRef] [PubMed] 
2. Kessler, R.C.; McGongle, K.A.; Zhao, S.; Nelson, C.B.; Hughes, M.; Eshleman, S.; Wittchen, H.-U.; Kendler, K.S. Lifetime and 12-month prevalence of DSM-III-R psychiatric disorders in the United States. Arch. Gen. Psychiatry 1994, 51, 8-19. [CrossRef] [PubMed]

3. Lu, Y.; Tang, C.; Liow, C.S.; Ng, W.W.N.; Ho, C.S.H.; Ho, R.C.M. A regressional analysis of maladaptive rumination, illness perception and negative emotional outcomes in Asian patients suffering from depressive disorder. Asian J. Psychiatry 2014, 12, 69-76. [CrossRef] [PubMed]

4. Choo, C.; Diederich, J.; Song, I.; Ho, R. Cluster analysis reveals risk factors for repeated suicide attempts in a multi-ethnic Asian population. Asian J. Psychiatry 2014, 8, 38-42. [CrossRef] [PubMed]

5. Large, M. Suicide Risk and Intervention in Mental Illness Study on suicide risk assessment in mental illness underestimates inpatient suicide risk. Br. Med. J. 2016, 532, i267. [CrossRef] [PubMed]

6. Cuijpers, P.; Smit, H. Excess mortality in depression: A meta-analysis of community studies. J. Affect. Disord. 2002, 72, 227-236. [CrossRef]

7. Stewart, W.F.S.; Ricci, J.A.; Chee, E.; Hahn, S.R.; Morganstein, D. Cost of lost productive work time among US workers with depression. Eur. J. Public Health 2005, 15, 26.

8. Daly, E.J.; Trivedi, M.H.; Wisniewski, S.R.; Nierenberg, A.A.; Gaynes, B.N.; Warden, D.; Morris, D.W.; Luther, J.F.; Farabaugh, A.; Cook, I.; et al. Health-related quality of life in depression: A STAR*D report. Ann. Clin. Psychiatry 2010, 22, 43-55.

9. Mayor, S. Persistent depression doubles stroke risk despite treatment, study finds. BMJ Clin. Res. Ed. 2015, 350, h2611. [CrossRef]

10. Lim, G.Y.; Tam, W.W.; Lu, Y.; Ho, C.S.; Zhang, M.W.; Ho, R.C. Prevalence of Depression in the Community from 30 Countries between 1994 and 2014. Sci. Rep. 2018, 8, 2861. [CrossRef]

11. Cowen, P.J. Backing into the future: Pharmacological approaches to the management of resistant depression. Psychol. Med. 2017, 47, 2569-2577. [CrossRef] [PubMed]

12. Simon, G.E.; Khandker, R.K.; Ichikawa, L.; Operskalski, B.H. Recovery from depression predicts lower health services costs. J. Clin. Psychiatry 2006, 67, 1226-1231. [CrossRef] [PubMed]

13. Kang, E.; Lee, J. A longitudinal study on the causal association between smoking and depression. J. Prev. Med. Public Health = Yebang Uihakhoe Chi 2010, 43, 193-204. [CrossRef] [PubMed]

14. Sullivan, L.E.; Fiellin, D.A.; O'Connor, P.G. The prevalence and impact of alcohol problems in major depression: A systematic review. Am. J. Med. 2005, 118, 330-341. [CrossRef] [PubMed]

15. Schachter, J.; Martel, J.; Lin, C.-S.; Chang, C.-J.; Wu, T.-R.; Lu, C.-C.; Ko, Y.-F.; Lai, H.-C.; Ojcius, D.M.; Young, J.D. Effects of obesity on depression: A role for inflammation and the gut microbiota. Brain Behav. Immun. 2018, 69, 1-8. [CrossRef] [PubMed]

16. Dinas, P.C.; Koutedakis, Y.; Flouris, A.D. Effects of exercise and physical activity on depression. Ir. J. Med. Sci. 2011, 180, 319-325. [CrossRef] [PubMed]

17. Dong, X.; Yang, C.; Cao, S.; Gan, Y.; Sun, H.; Gong, Y.; Yang, H.; Yin, X.; Lu, Z. Tea consumption and the risk of depression: A meta-analysis of observational studies. Aust. N. Z. J. Psychiatry 2015, 49, 334-345. [CrossRef]

18. Khan, N.; Mukhtar, H. Tea and Health: Studies in Humans. Curr. Pharm. Des. 2013, 19, 6141-6147. [CrossRef]

19. da Silva Pinto, M. Tea: A new perspective on health benefits. Food Res. Int. 2013, 53, 558-567. [CrossRef]

20. Legeay, S.; Rodier, M.; Fillon, L.; Faure, S.; Clere, N. Epigallocatechin Gallate: A Review of Its Beneficial Properties to Prevent Metabolic Syndrome. Nutrients 2015, 7, 5443-5468. [CrossRef]

21. Villas Boas, G.R.; Boerngen de Lacerda, R.; Paes, M.M.; Gubert, P.; Almeida, W.L.d.C.; Rescia, V.C.; de Carvalho, P.M.G.; de Carvalho, A.A.V.; Oesterreich, S.A. Molecular aspects of depression: A review from neurobiology to treatment. Eur. J. Pharmacol. 2019, 851, 99-121. [CrossRef] [PubMed]

22. Ferrari, F.; Villa, R.F. The Neurobiology of Depression: An Integrated Overview from Biological Theories to Clinical Evidence. Mol. Neurobiol. 2017, 54, 4847-4865. [CrossRef] [PubMed]

23. Dean, J.; Keshavan, M. The neurobiology of depression: An integrated view. Asian J. Psychiatry 2017, 27, 101-111. [CrossRef] [PubMed]

24. Ruusunen, A.; Lehto, S.M.; Tolmunen, T.; Mursu, J.; Kaplan, G.A.; Voutilainen, S. Coffee, tea and caffeine intake and the risk of severe depression in middle-aged Finnish men: The Kuopio Ischaemic Heart Disease Risk Factor Study. Public Health Nutr. 2010, 13, 1215-1220. [CrossRef] [PubMed] 
25. Masana, M.F.; Maria Haro, J.; Mariolis, A.; Piscopo, S.; Valacchi, G.; Bountziouka, V.; Anastasiou, F.; Zeimbekis, A.; Tyrovola, D.; Gotsis, E.; et al. Mediterranean diet and depression among older individuals: The multinational MEDIS study. Exp. Gerontol. 2018, 110, 67-72. [CrossRef] [PubMed]

26. Kim, J. Green Tea, Coffee, and Caffeine Consumption Are Inversely Associated with Self-Report Lifetime Depression in the Korean Population. Nutrients 2018, 10, 1201. [CrossRef] [PubMed]

27. Zhang, Q.Y.; Yang, H.C.; Wang, J.; Li, A.W.; Zhang, W.T.; Cui, X.H.; Wang, K.L. Effect of green tea on reward learning in healthy individuals: A randomized, double-blind, placebo-controlled pilot study. Nutr. J. 2013, 12, 84. [CrossRef]

28. Kendler, K.S. Toward a philosophical structure for psychiatry. Am. J. Psychiatry 2005, 162, 433-440. [CrossRef]

29. Chang, S.C.; Cassidy, A.; Willett, W.C.; Rimm, E.B.; O’Reilly, E.J.; Okereke, O.I. Dietary flavonoid intake and risk of incident depression in midlife and older women. Am. J. Clin. Nutr. 2016, 104, 704-714. [CrossRef]

30. Chang, X.R.; Wang, L.; Li, J.; Wu, D.S. Analysis of anti-depressant potential of curcumin against depression induced male albino wistar rats. Brain Res. 2016, 1642, 219-225. [CrossRef]

31. Unno, K.; Hara, A.; Nakagawa, A.; Iguchi, K.; Ohshio, M.; Morita, A.; Nakamura, Y. Anti-stress effects of drinking green tea with lowered caffeine and enriched theanine, epigallocatechin and arginine on psychosocial stress induced adrenal hypertrophy in mice. Phytomedicine 2016, 23, 1365-1374. [CrossRef] [PubMed]

32. Wang, D.X.; Cai, M.; Wang, T.T.; Zhao, G.S.; Huang, J.B.; Wang, H.S.; Qian, F.; Ho, C.T.; Wang, Y.J. Theanine supplementation prevents liver injury and heat shock response by normalizing hypothalamic-pituitaryadrenal axis hyperactivity in mice subjected to whole body heat stress. J. Funct. Foods 2018, 45, 181-189. [CrossRef]

33. Wang, D.X.; Gao, Q.; Zhao, G.S.; Kan, Z.P.; Wang, X.X.; Wang, H.S.; Huang, J.B.; Wang, T.T.; Qian, F.; Ho, C.T.; et al. Protective Effect and Mechanism of Theanine on Lipopolysaccharide-Induced Inflammation and Acute Liver Injury in Mice. J. Agr. Food Chem. 2018, 66, 7674-7683. [CrossRef] [PubMed]

34. Zhu, W.L.; Shi, H.S.; Wei, Y.M.; Wang, S.J.; Sun, C.Y.; Ding, Z.B.; Lu, L. Green tea polyphenols produce antidepressant-like effects in adult mice. Pharmacol. Res. 2012, 65, 74-80. [CrossRef]

35. Zhao, X.; Liu, F.; Jin, H.; Li, R.; Wang, Y.; Zhang, W.; Wang, H.; Chen, W. Involvement of PKC Alpha and Erk1/2 Signaling Pathways in EGCG's Protection Against Stress-Induced Neural Injuries in Wistar Rats. Neuroscience 2017, 346, 226-237. [CrossRef] [PubMed]

36. Lee, B.; Shim, I.; Lee, H.; Hahm, D.-H. Effects of Epigallocatechin Gallate on Behavioral and Cognitive Impairments, Hypothalamic-Pituitary-Adrenal Axis Dysfunction, and Alternations in Hippocampal BDNF Expression Under Single Prolonged Stress. J. Med. Food 2018, 21, 979-989. [CrossRef]

37. Bae, J.H.; Mun, K.C.; Park, W.K.; Lee, S.R.; Suh, S.I.; Baek, W.K.; Yim, M.B.; Kwon, T.K.; Song, D.K. EGCG attenuates AMPA-induced intracellular calcium increase in hippocampal neurons. Biochem. Biophys. Res. Commun. 2002, 290, 1506-1512.

38. Jeong, H.S.; Kim, Y.S.; Park, J.S. Modulation of neuronal activity by EGCG. Brain Res. 2005, 1047, $267-270$. [CrossRef]

39. Yi, Q.Y.; Li, H.B.; Qi, J.; Yu, X.J.; Huo, C.J.; Li, X.; Bai, J.; Gao, H.L.; Kou, B.; Liu, K.L.; et al. Chronic infusion of epigallocatechin-3-O-gallate into the hypothalamic paraventricular nucleus attenuates hypertension and sympathoexcitation by restoring neurotransmitters and cytokines. Toxicol. Lett. 2016, 262, 105-113. [CrossRef]

40. Ye, Q.Y.; Ye, L.F.; Xu, X.J.; Huang, B.X.; Zhang, X.D.; Zhu, Y.G.; Chen, X.C. Epigallocatechin-3-gallate suppresses 1-methyl-4-phenyl-pyridine-induced oxidative stress in PC12 cells via the SIRT1/PGC-1 alpha signaling pathway. BMC Complement. Altern. Med. 2012, 12, 82. [CrossRef]

41. Unno, K.; Noda, S.; Kawasaki, Y.; Yamada, H.; Morita, A.; Iguchi, K.; Nakamura, Y. Reduced Stress and Improved Sleep Quality Caused by Green Tea Are Associated with a Reduced Caffeine Content. Nutrients 2017, 9, 777. [CrossRef]

42. Yoto, A.; Murao, S.; Nakamura, Y.; Yokogoshi, H. Intake of green tea inhibited increase of salivary chromogranin A after mental task stress loads. J. Physiol. Anthropol. 2014, 33, 20. [CrossRef] [PubMed]

43. Yoto, A.; Fukui, N.; Kaneda, C.; Torita, S.; Goto, K.; Nanjo, F.; Yokogoshi, H. Black tea aroma inhibited increase of salivary chromogranin-A after arithmetic tasks. J. Physiol. Anthropol. 2018, 37. [CrossRef] [PubMed]

44. Yoto, A.; Yokogoshi, H.; Moriyama, T.; Nakamura, Y.; Katsuno, T.; Nakayama, T. Effect of Smelling Green Tea Rich in Aroma Components on EEG Activity and Memory Task Performance. In Proceedings of the 
2013 International Conference on Biometrics and Kansei Engineering (ICBAKE), Tokyo, Japan, 5-7 July 2013; pp. 76-81.

45. Vargas, N.; Marino, F. Heat stress, gastrointestinal permeability and interleukin-6 signaling-Implications for exercise performance and fatigue. Temperature 2016, 3, 240-251. [CrossRef] [PubMed]

46. Evanson, N.K.; van Hooren, D.C.; Herman, J.P. GluR5-mediated glutamate signaling regulates hypothalamo-pituitary-adrenocortical stress responses at the paraventricular nucleus and median eminence. Psychoneuroendocrinology 2009, 34, 1370-1379. [CrossRef] [PubMed]

47. Zelena, D.; Mergl, Z.; Makara, G.B. Glutamate agonists activate the hypothalamic-pituitary-adrenal axis through hypothalamic paraventricular nucleus but not through vasopressinerg neurons. Brain Res. 2005, 1031, 185-193. [CrossRef] [PubMed]

48. Kakuda, T. Neuroprotective effects of theanine and its preventive effects on cognitive dysfunction. Pharmacol. Res. 2011, 64, 162-168. [CrossRef] [PubMed]

49. Inoue, K.; Miyazaki, Y.; Unno, K.; Min, J.Z.; Todoroki, K.; Toyo'oka, T. Stable isotope dilution HILIC-MS/MS method for accurate quantification of glutamic acid, glutamine, pyroglutamic acid, GABA and theanine in mouse brain tissues. Biomed. Chromatogr. 2016, 30, 55-61. [CrossRef]

50. Hyland, N.P.; Cryan, J.F. A gut feeling about GABA: Focus on GABA(B) receptors. Front. Pharmacol. 2010, 1, 124. [CrossRef]

51. Unno, K.; Fujitani, K.; Takamori, N.; Takabayashi, F.; Maeda, K.; Miyazaki, H.; Tanida, N.; Iguchi, K.; Shimoi, K.; Hoshino, M. Theanine intake improves the shortened lifespan, cognitive dysfunction and behavioural depression that are induced by chronic psychosocial stress in mice. Free Radic. Res. 2011, 45, 966-974. [CrossRef]

52. Unno, K.; Iguchi, K.; Tanida, N.; Fujitani, K.; Takamori, N.; Yamamoto, H.; Ishii, N.; Nagano, H.; Nagashima, T.; Hara, A.; et al. Ingestion of theanine, an amino acid in tea, suppresses psychosocial stress in mice. Exp. Physiol. 2013, 98, 290-303. [CrossRef] [PubMed]

53. Kadowaki, M.; Sugihara, N.; Tagashira, T.; Terao, K.; Furuno, K. Presence or absence of a gallate moiety on catechins affects their cellular transport. J. Pharm. Pharmacol. 2008, 60, 1189-1195. [CrossRef] [PubMed]

54. Annaba, F.; Kumar, P.; Dudeja, A.K.; Saksena, S.; Gill, R.K.; Alrefai, W.A. Green tea catechin EGCG inhibits ileal apical sodium bile acid transporter ASBT. Am. J. Physiol.-Gastrointest. Liver Physiol. 2010, 298, G467-G473. [CrossRef] [PubMed]

55. Farabegoli, F.; Papi, A.; Bartolini, G.; Ostan, R.; Orlandi, M. (-)-Epigallocatechin-3-gallate downregulates Pg-P and BCRP in a tamoxifen resistant MCF-7 cell line. Phytomedicine 2010, 17, 356-362. [CrossRef] [PubMed]

56. Yamada, T.; Terashima, T.; Kawano, S.; Furuno, R.; Okubo, T.; Juneja, L.R.; Yokogoshi, H. Theanine, gamma-glutamylethylamide, a unique amino acid in tea leaves, modulates neurotransmitter concentrations in the brain striatum interstitium in conscious rats. Amino Acids 2009, 36, 21-27. [CrossRef]

57. Legendre, P. The glycinergic inhibitory synapse. Cell. Mol. Life Sci. 2001, 58, 760-793. [CrossRef] [PubMed]

58. Eulenburg, V.; Armsen, W.; Betz, H.; Gomeza, J. Glycine transporters: Essential regulators of neurotransmission. Trends Biochem. Sci. 2005, 30, 325-333. [CrossRef] [PubMed]

59. Yadid, G.; Pacak, K.; Golomb, E.; Harvey-White, J.D.; Lieberman, D.M.; Kopin, I.J.; Goldstein, D.S. Glycine stimulates striatal dopamine release in conscious rats. Br. J. Pharmacol. 1993, 110, 50-53. [CrossRef] [PubMed]

60. Schuster, J.; Mitchell, E.S. More than just caffeine: Psychopharmacology of methylxanthine interactions with plant-derived phytochemicals. Prog. Neuro-Psychopharmacol. Biol. Psychiatry 2019, 89, 263-274. [CrossRef]

61. Lee, H.; Bae, J.H.; Lee, S.R. Protective effect of green tea polyphenol EGCG against neuronal damage and brain edema after unilateral cerebral ischemia in gerbils. J. Neurosci. Res. 2004, 77, 892-900. [CrossRef]

62. Nater, U.M.; Rohleder, N. Salivary alpha-amylase as a non-invasive biomarker for the sympathetic nervous system: Current state of research. Psychoneuroendocrinology 2009, 34, 486-496. [CrossRef] [PubMed]

63. Almela, M.; Hidalgo, V.; Villada, C.; van der Meij, L.; Espin, L.; Gomez-Amor, J.; Salvador, A. Salivary alpha-amylase response to acute psychosocial stress: The impact of age. Biol. Psychol. 2011, 87, 421-429. [CrossRef] [PubMed]

64. Nater, U.M.; La Marca, R.; Florin, L.; Moses, A.; Langhans, W.; Koller, M.M.; Ehlert, U. Stress-induced changes in human salivary alpha-amylase activity-associations with adrenergic activity. Psychoneuroendocrinology 2006, 31, 49-58. [CrossRef] [PubMed] 
65. Nater, U.M.; Rohleder, N.; Schlotz, W.; Ehlert, U.; Kirschbaum, C. Determinants of the diurnal course of salivary alpha-amylase. Psychoneuroendocrinology 2007, 32, 392-401. [CrossRef] [PubMed]

66. Lovato, N.; Gradisar, M. A meta-analysis and model of the relationship between sleep and depression in adolescents: Recommendations for future research and clinical practice. Sleep Med. Rev. 2014, 18, 521-529. [CrossRef] [PubMed]

67. Kim, S.; Jo, K.; Hong, K.B.; Han, S.H.; Suh, H.J. GABA and 1-theanine mixture decreases sleep latency and improves NREM sleep. Pharm. Biol. 2019, 57, 65-73. [CrossRef] [PubMed]

68. Daglia, M.; Di Lorenzo, A.; Nabavi, S.F.; Sureda, A.; Khanjani, S.; Moghaddam, A.H.; Braidy, N.; Nabavi, S.M. Improvement of Antioxidant Defences and Mood Status by Oral GABA Tea Administration in a Mouse Model of Post-Stroke Depression. Nutrients 2017, 9, 446. [CrossRef] [PubMed]

69. Mahoney, C.R.; Giles, G.E.; Marriott, B.P.; Judelson, D.A.; Glickman, E.L.; Geiselman, P.J.; Lieberman, H.R. Intake of caffeine from all sources and reasons for use by college students. Clin. Nutr. (Edinburgh) 2019, 38, 668-675. [CrossRef]

70. Unno, K.; Tanida, N.; Ishii, N.; Yamamoto, H.; Iguchi, K.; Hoshino, M.; Takeda, A.; Ozawa, H.; Ohkubo, T.; Juneja, L.R.; et al. Anti-stress effect of theanine on students during pharmacy practice: Positive correlation among salivary $\alpha$-amylase activity, trait anxiety and subjective stress. Pharmacol. Biochem. Behav. 2013, 111, 128-135. [CrossRef]

71. Wang, J.Q.; Mao, L. The ERK Pathway: Molecular Mechanisms and Treatment of Depression. Mol. Neurobiol. 2019. [CrossRef]

72. Wang, L.; Peng, D.; Xie, B.; Jiang, K.; Fang, Y. The extracellular signal-regulated kinase pathway may play an important role in mediating antidepressant-stimulated hippocampus neurogenesis in depression. Med. Hypotheses 2012, 79, 87-91. [CrossRef] [PubMed]

73. Pahlevani, P.; Fatahi, Z.; Moradi, M.; Haghparast, A. Morphine-induced conditioned place preference and the alterations of p-ERK, p-CREB and c-fos levels in hypothalamus and hippocampus: The effects of physical stress. Cell. Mol. Biol. 2014, 60, 48-55. [PubMed]

74. Dwivedi, Y.; Rizavi, H.S.; Conley, R.R.; Pandey, G.N. ERK MAP kinase signaling in post-mortem brain of suicide subjects: Differential regulation of upstream Raf kinases Raf-1 and B-Raf. Mol. Psychiatry 2006, 11, 86-98. [CrossRef] [PubMed]

75. Yao, C.; Zhang, J.; Liu, G.; Chen, F.; Lin, Y. Neuroprotection by (-)-epigallocatechin-3-gallate in a rat model of stroke is mediated through inhibition of endoplasmic reticulum stress. Mol. Med. Rep. 2014, 9, 69-76. [CrossRef] [PubMed]

76. Johnston, G.A. Flavonoid nutraceuticals and ionotropic receptors for the inhibitory neurotransmitter GABA. Neurochem. Int. 2015, 89, 120-125. [CrossRef] [PubMed]

77. Alho, H.; Costa, E.; Ferrero, P.; Fujimoto, M.; Cosenza-Murphy, D.; Guidotti, A. Diazepam-binding inhibitor: A neuropeptide located in selected neuronal populations of rat brain. Science (New York) 1985, 229, 179-182. [CrossRef]

78. Chang, K.-C.; Yang, J.J.; Wang-Hsu, E.C.-H.; Chiu, T.-H.; Hsu, F.-C. (-)Epigallocatechin-3-gallate inhibits the spontaneous firing of rat locus coeruleus neuron. Neurosci. Lett. 2009, 452, 141-145. [CrossRef]

79. Lee, M.-S.; Lee, S.; Doo, M.; Kim, Y. Green Tea (-)-Epigallotocatechin-3-Gallate Induces PGC-1alpha Gene Expression in HepG2 Cells and 3T3-L1 Adipocytes. Prev. Nutr. Food Sci. 2016, 21, 62-67. [CrossRef]

80. Zhan, G.; Huang, N.; Li, S.; Hua, D.; Zhang, J.; Fang, X.; Yang, N.; Luo, A.; Yang, C. PGC-1 alpha-FNDC5-BDNF signaling pathway in skeletal muscle confers resilience to stress in mice subjected to chronic social defeat. Psychopharmacology 2018, 235, 3351-3358. [CrossRef]

81. Cunha, M.P.; Pazini, F.L.; Lieberknecht, V.; Rodrigues, A.L.S. Subchronic administration of creatine produces antidepressant-like effect by modulating hippocampal signaling pathway mediated by FNDC5/BDNF/Akt in mice. J. Psychiatr. Res. 2018, 104, 78-87. [CrossRef]

82. Lucas, E.K.; Dougherty, S.E.; McMeekin, L.J.; Reid, C.S.; Dobrunz, L.E.; West, A.B.; Hablitz, J.J.; Cowell, R.M. PGC-1 alpha Provides a Transcriptional Framework for Synchronous Neurotransmitter Release from Parvalbumin-Positive Interneurons. J. Neurosci. 2014, 34, 14375-14387. [CrossRef] [PubMed]

83. Dougherty, S.E.; Bartley, A.F.; Lucas, E.K.; Hablitz, J.J.; Dobrunz, L.E.; Cowell, R.M. Mice Lacking the Transcriptional Coactivator Pgc-1 Alpha Exhibit Alterations in Inhibitory Synaptic Transmission in the Motor Cortex. Neuroscience 2014, 271, 137-148. [CrossRef] [PubMed] 
84. Felger, J.C.; Lotrich, F.E. Inflammatory Cytokines in Depression: Neurobiological Mechanisms and Therapeutic Implications. Neuroscience 2013, 246, 199-229. [CrossRef] [PubMed]

85. Leonard, B.E. Inflammation and depression: A causal or coincidental link to the pathophysiology? Acta Neuropsychiatr. 2018, 30, 1-16. [CrossRef] [PubMed]

86. Anders, S.; Tanaka, M.; Kinney, D.K. Depression as an evolutionary strategy for defense against infection. Brain Behav. Immun. 2013, 31, 9-22. [CrossRef] [PubMed]

87. Rosenblat, J.D.; Cha, D.S.; Mansur, R.B.; McIntyre, R.S. Inflamed moods: A review of the interactions between inflammation and mood disorders. Prog. Neuro-Psychopharmacol. Biol. Psychiatry 2014, 53, 23-34. [CrossRef] [PubMed]

88. Gao, W.Q.; Wang, W.; Peng, Y.; Deng, Z.F. Antidepressive effects of kaempferol mediated by reduction of oxidative stress, proinflammatory cytokines and up-regulation of AKT/beta-catenin cascade. Metab. Brain Dis. 2019, 34, 485-494. [CrossRef]

89. Xu, Y.; Lin, W.J. Anti-inflammatory Cytokines and Depression. Prog. Biochem. Biophys. 2014, 41, 1099-1108.

90. Skaper, S.D.; Facci, L.; Zusso, M.; Giusti, P. An Inflammation-Centric View of Neurological Disease: Beyond the Neuron. Front. Cell. Neurosci. 2018, 12, 72. [CrossRef]

91. Ano, Y.; Ohya, R.; Kita, M.; Taniguchi, Y.; Kondo, K. Theaflavins Improve Memory Impairment and Depression-Like Behavior by Regulating Microglial Activation. Molecules 2019, 24, 467. [CrossRef]

92. Wu, Y.T.; Jin, F.J.; Wang, Y.L.; Li, F.; Wang, L.; Wang, Q.L.; Ren, Z.; Wang, Y.F. In vitro and in vivo anti-inflammatory effects of theaflavin-3,3'-digallate on lipopolysaccharide-induced inflammation. Eur. J. Pharmacol. 2017, 794, 52-60. [CrossRef] [PubMed]

93. Ko, H.J.; Lo, C.Y.; Wang, B.J.; Chiou, R.Y.Y.; Lin, S.M. Theaflavin-3,3'-digallate, a black tea polyphenol, attenuates adipocyte-activated inflammatory response of macrophage associated with the switch of M1/M2-like phenotype. J. Funct. Foods 2014, 11, 36-48. [CrossRef]

94. Li, J.H.; Sasaki, G.Y.; Dey, P.; Chitchumroonchokchai, C.; Labyk, A.N.; McDonald, J.D.; Kim, J.B.; Bruno, R.S. Green tea extract protects against hepatic NF kappa B activation along the gut-liver axis in diet-induced obese mice with nonalcoholic steatohepatitis by reducing endotoxin and TLR4/MyD88 signaling. J. Nutr. Biochem. 2018, 53, 58-65. [CrossRef] [PubMed]

95. Mi, Y.S.; Qi, G.Y.; Fan, R.; Qiao, Q.L.; Sun, Y.L.; Gao, Y.Q.; Liu, X.B. EGCG ameliorates high-fat- and high-fructose-induced cognitive defects by regulating the IRS/AKT and ERK/CREB/BDNF signaling pathways in the CNS. FASEB J. 2017, 31, 4998-5011. [CrossRef] [PubMed]

96. Fechtner, S.; Singh, A.; Chourasia, M.; Ahmed, S. Molecular insights into the differences in anti-inflammatory activities of green tea catechins on IL-1 beta signaling in rheumatoid arthritis synovial fibroblasts. Toxicol. Appl. Pharmacol. 2017, 329, 112-120. [CrossRef]

97. Liang, Y.; Ip, M.S.M.; Mak, J.C.W. (-)-Epigallocatechin-3-gallate suppresses cigarette smoke-induced inflammation in human cardiomyocytes via ROS-mediated MAPK and NF-kappaB pathways. Phytomed. Int. J. Phytother. Phytopharmacol. 2019, 58, 152768.

98. Li, K.K.; Peng, J.M.; Zhu, W.; Cheng, B.H.; Li, C.M. Gallocatechin gallate (GCG) inhibits 3T3-L1 differentiation and lipopolysaccharide induced inflammation through MAPK and NF-kappa B signaling. J. Funct. Foods 2017, 30, 159-167. [CrossRef]

99. Novilla, A.; Djamhuri, D.S.; Nurhayati, B.; Rihibiha, D.D.; Afifah, E.; Widowati, W. Anti-inflammatory properties of oolong tea (Camellia sinensis) ethanol extract and epigallocatechin gallate in LPS-induced RAW 264.7 cells. Asian Pac. J. Trop. Biomed. 2017, 7, 1005-1009. [CrossRef]

100. Seok, J.K.; Lee, J.W.; Kim, Y.M.; Boo, Y.C. Punicalagin and (-)-Epigallocatechin-3-Gallate Rescue Cell Viability and Attenuate Inflammatory Responses of Human Epidermal Keratinocytes Exposed to Airborne Particulate Matter PM10. Skin Pharmacol. Physiol. 2018, 31, 134-143. [CrossRef]

101. Yoon, J.Y.; Kwon, H.H.; Min, S.U.; Thiboutot, D.M.; Suh, D.H. Epigallocatechin-3-Gallate Improves Acne in Humans by Modulating Intracellular Molecular Targets and Inhibiting P. acnes. J. Investig. Dermatol. 2013, 133, 429-440. [CrossRef]

102. Fan, Y.J.; Piao, C.H.; Hyeon, E.; Jung, S.Y.; Eoin, J.E.; Shin, H.S.; Song, C.H.; Chai, O.H. Gallic acid alleviates nasal inflammation via activation of Th1 and inhibition of Th2 and Th17 in a mouse model of allergic rhinitis. Int. Immunopharmacol. 2019, 70, 512-519. [CrossRef] [PubMed]

103. Zeng, W.J.; Tan, Z.; Lai, X.F.; Xu, Y.N.; Mai, C.L.; Zhang, J.; Lin, Z.J.; Liu, X.G.; Sun, S.L.; Zhou, L.J. Topical delivery of L-theanine ameliorates TPA-induced acute skin inflammation via downregulating endothelial 
PECAM-1 and neutrophil infiltration and activation. Chem.-Biol. Interact. 2018, 284, 69-79. [CrossRef] [PubMed]

104. Hwang, Y.P.; Jin, S.W.; Choi, J.H.; Choi, C.Y.; Kim, H.G.; Kim, S.J.; Kim, Y.; Lee, K.J.; Chung, Y.C.; Jeong, H.G. Inhibitory effects of L-theanine on airway inflammation in ovalbumin-induced allergic asthma. Food Chem. Toxicol. 2017, 99, 162-169. [CrossRef] [PubMed]

105. Wang, S.; Huang, X.F.; Zhang, P.; Newell, K.A.; Wang, H.; Zheng, K.; Yu, Y. Dietary teasaponin ameliorates alteration of gut microbiota and cognitive decline in diet-induced obese mice. Sci. Rep. 2017, 7, 12203. [CrossRef] [PubMed]

106. Hinz, M.; Stein, A.; Uncini, T. The discrediting of the monoamine hypothesis. Int. J. Gen. Med. 2012, 5, 135-142. [CrossRef]

107. Clevenger, S.S.; Malhotra, D.; Dang, J.; Vanle, B.; IsHak, W.W. The role of selective serotonin reuptake inhibitors in preventing relapse of major depressive disorder. Ther. Adv. Psychopharmacol. 2018, 8, 49-58. [CrossRef]

108. Brezun, J.M.; Daszuta, A. Serotonergic reinnervation reverses lesion-induced decreases in PSA-NCAM labeling and proliferation of hippocampal cells in adult rats. Hippocampus 2000, 10, 37-46. [CrossRef]

109. Nestler, E.J.; Carlezon, W.A. The mesolimbic dopamine reward circuit in depression. Biol. Psychiatry 2006, 59, 1151-1159. [CrossRef]

110. El Mansari, M.; Guiard, B.P.; Chernoloz, O.; Ghanbari, R.; Katz, N.; Blier, P. Relevance of Norepinephrine-Dopamine Interactions in the Treatment of Major Depressive Disorder. CNS Neurosci. Ther. 2010, 16, e1-e17. [CrossRef]

111. Shen, M.J.; Yang, Y.; Wu, Y.; Zhang, B.B.; Wu, H.S.; Wang, L.; Tang, H.; Chen, J.D. L-theanine ameliorate depressive-like behavior in a chronic unpredictable mild stress rat model via modulating the monoamine levels in limbic-cortical-striatal-pallidal-thalamic-circuit related brain regions. Phytother. Res. 2019, 33, 412-421. [CrossRef]

112. Zhu, G.; Yang, S.; Xie, Z.; Wan, X. Synaptic modification by L-theanine, a natural constituent in green tea, rescues the impairment of hippocampal long-term potentiation and memory in AD mice. Neuropharmacology 2018, 138, 331-340. [CrossRef] [PubMed]

113. Ikram, H.; Mirza, B.; Haleem, D.J. Neurochemical and behavioral effects of green tea (Camellia sinensis) as observed in animals exposed to restraint stress. Pak. J. Pharm. Sci. 2017, 30, 487-492. [PubMed]

114. Stringer, T.P.; Guerrieri, D.; Vivar, C.; van Praag, H. Plant-derived flavanol (-)epicatechin mitigates anxiety in association with elevated hippocampal monoamine and BDNF levels, but does not influence pattern separation in mice. Transl. Psychiatry 2015, 5, e493. [CrossRef] [PubMed]

115. Liu, Y.; Jia, G.G.; Gou, L.S.; Sun, L.Y.; Fu, X.B.; Lan, N.; Li, S.; Yin, X.X. Antidepressant-like effects of tea polyphenols on mouse model of chronic unpredictable mild stress. Pharmacol. Biochem. Behav. 2013, 104, 27-32. [CrossRef] [PubMed]

116. Janssens, P.L.H.R.; Penders, J.; Hursel, R.; Budding, A.E.; Savelkoul, P.H.M.; Westerterp-Plantenga, M.S. Long-Term Green Tea Supplementation Does Not Change the Human Gut Microbiota. PLoS ONE 2016, 11, e0153134. [CrossRef] [PubMed]

117. Henning, S.M.; Yang, J.; Hsu, M.; Lee, R.P.; Grojean, E.M.; Ly, A.; Tseng, C.H.; Heber, D.; Li, Z. Decaffeinated green and black tea polyphenols decrease weight gain and alter microbiome populations and function in diet-induced obese mice. Eur. J. Nutr. 2018, 57, 2759-2769. [CrossRef] [PubMed]

118. Zhang, X.; Zhu, X.L.; Sun, Y.K.; Hu, B.; Sun, Y.; Jabbar, S.; Zeng, X.X. Fermentation in vitro of EGCG, GCG and EGCG3" Me isolated from Oolong tea by human intestinal microbiota. Food Res. Int. 2013, 54, 1589-1595. [CrossRef]

119. Bustos, I.; Garcia-Cayuela, T.; Hernandez-Ledesma, B.; Pelaez, C.; Requena, T.; Martinez-Cuesta, M.C. Effect of flavan-3-ols on the adhesion of potential probiotic lactobacilli to intestinal cells. J. Agric. Food Chem. 2012, 60, 9082-9088. [CrossRef] [PubMed]

120. Kita, M.; Uchida, S.; Yamada, K.; Ano, Y. Anxiolytic effects of theaflavins via dopaminergic activation in the frontal cortex. Biosci. Biotechnol. Biochem. 2019, 1-6. [CrossRef] [PubMed]

121. Anandhan, A.; Janakiraman, U.; Manivasagam, T. Theaflavin ameliorates behavioral deficits, biochemical indices and monoamine transporters expression against subacute 1-methyl-4-phenyl-1,2,3,6-tetrahydropyridine (MPTP)-induced mouse model of Parkinson's disease. Neuroscience 2012, 218, 257-267. [CrossRef] 
122. Tzounis, X.; Vulevic, J.; Kuhnle, G.G.C.; George, T.; Leonczak, J.; Gibson, G.R.; Kwik-Uribe, C.; Spencer, J.P.E. Flavanol monomer-induced changes to the human faecal microflora. Br. J. Nutr. 2008, 99, 782-792. [CrossRef] [PubMed]

123. Cheng, M.; Zhang, X.; Miao, Y.; Cao, J.; Wu, Z.; Weng, P. The modulatory effect of (-)-epigallocatechin 3-O-(3-O-methyl) gallate (EGCG3"Me) on intestinal microbiota of high fat diet-induced obesity mice model. Food Res. Int. 2017, 92, 9-16. [CrossRef] [PubMed]

124. Drevets, W.C.; Price, J.L.; Furey, M.L. Brain structural and functional abnormalities in mood disorders: Implications for neurocircuitry models of depression. Brain Struct. Funct. 2008, 213, 93-118. [CrossRef] [PubMed]

125. Hamon, M.; Blier, P. Monoamine neurocircuitry in depression and strategies for new treatments. Prog. Neuro-Psychopharmacol. Biol. Psychiatry 2013, 45, 54-63. [CrossRef] [PubMed]

126. Henn, F.A.; Vollmayr, B. Stress models of depression: Forming genetically vulnerable strains. Neurosci. Biobehav. Rev. 2005, 29, 799-804. [CrossRef] [PubMed]

127. Zang, L.Y.; Misra, H.P. Generation of reactive oxygen species during the monoamine oxidase-catalyzed oxidation of the neurotoxicant, 1-methyl-4-phenyl-1,2,3,6-tetrahydropyridine. J. Biol. Chem. 1993, 268, 16504-16512.

128. Khan, H.; Perviz, S.; Sureda, A.; Nabavi, S.M.; Tejada, S. Current standing of plant derived flavonoids as an antidepressant. Food Chem. Toxicol. 2018, 119, 176-188. [CrossRef] [PubMed]

129. Martins, J.; Brijesh, S. Phytochemistry and pharmacology of anti-depressant medicinal plants: A review. Biomed. Pharmacother. 2018, 104, 343-365. [CrossRef]

130. Kolla, N.J.; Chiuccariello, L.; Wilson, A.A.; Houle, S.; Links, P.; Bagby, R.M.; McMain, S.; Kellow, C.; Patel, J.; Rekkas, P.V.; et al. Elevated Monoamine Oxidase-A Distribution Volume in Borderline Personality Disorder Is Associated with Severity Across Mood Symptoms, Suicidality, and Cognition. Biol. Psychiatry 2016, 79, 117-126. [CrossRef]

131. Bandaruk, Y.; Mukai, R.; Kawamura, T.; Nemoto, H.; Terao, J. Evaluation of the inhibitory effects of quercetin-related flavonoids and tea catechins on the monoamine oxidase-A reaction in mouse brain mitochondria. J. Agric. Food Chem. 2012, 60, 10270-10277. [CrossRef]

132. Mazzio, E.; Deiab, S.; Park, K.; Soliman, K.F.A. High throughput Screening to Identify Natural Human Monoamine Oxidase B Inhibitors. Phytother. Res. 2013, 27, 818-828. [CrossRef] [PubMed]

133. Lin, S.M.; Wang, S.W.; Ho, S.C.; Tang, Y.L. Protective effect of green tea (-)-epigallocatechin-3-gallate against the monoamine oxidase B enzyme activity increase in adult rat brains. Nutrition 2010, 26, 1195-1200. [CrossRef] [PubMed]

134. Ademosun, A.O.; Oboh, G. Comparison of the inhibition of monoamine oxidase and butyrylcholinesterase activities by infusions from green tea and some citrus peels. Int. J. Alzheimers Dis. 2014, 2014, 586407. [CrossRef] [PubMed]

135. Levites, Y.; Weinreb, O.; Maor, G.; Youdim, M.B.H.; Mandel, S. Green tea polyphenol (-)-epigallocatechin-3-gallate prevents N-methyl-4-phenyl-1,2,3,6-tetrahydropyridine-induced dopaminergic neurodegeneration. J. Neurochem. 2001, 78, 1073-1082. [CrossRef] [PubMed]

136. Dinan, T.G.; Cryan, J.F. The Microbiome-Gut-Brain Axis in Health and Disease. Gastroenterol. Clin. N. Am. 2017, 46, 77-89. [CrossRef] [PubMed]

137. Dinan, T.G.; Stilling, R.M.; Stanton, C.; Cryan, J.F. Collective unconscious: How gut microbes shape human behavior. J. Psychiatr. Res. 2015, 63, 1-9. [CrossRef] [PubMed]

138. Dinan, T.G.; Cryan, J.F. Mood by microbe: Towards clinical translation. Genome Med. 2016, 8, 36. [CrossRef]

139. Sudo, N.; Chida, Y.; Kubo, C. Postnatal microbial colonization programs the hypothalamic-pituitary-adrenal system for stress response in mice. J. Psychosom. Res. 2005, 58, S60. [CrossRef]

140. Neufeld, K.M.; Kang, N.; Bienenstock, J.; Foster, J.A. Reduced anxiety-like behavior and central neurochemical change in germ-free mice. Neurogastroenterol. Motil. 2011, 23, 255-264. [CrossRef]

141. Heijtza, R.D.; Wang, S.G.; Anuar, F.; Qian, Y.; Bjorkholm, B.; Samuelsson, A.; Hibberd, M.L.; Forssberg, H.; Pettersson, S. Normal gut microbiota modulates brain development and behavior. Proc. Natl. Acad. Sci. USA 2011, 108, 3047-3052. [CrossRef]

142. Lyte, M.; Li, W.; Opitz, N.; Gaykema, R.P.A.; Goehler, L.E. Induction of anxiety-like behavior in mice during the initial stages of infection with the agent of murine colonic hyperplasia Citrobacter rodentium. Physiol. Behav. 2006, 89, 350-357. [CrossRef] [PubMed] 
143. Luczynski, P.; Neufeld, K.A.M.; Oriach, C.S.; Clarke, G.; Dinan, T.G.; Cryan, J.F. Growing up in a Bubble: Using Germ-Free Animals to Assess the Influence of the Gut Microbiota on Brain and Behavior. Int. J. Neuropsychopharmacol. 2016, 19, pyw020. [CrossRef] [PubMed]

144. Bercik, P.; Denou, E.; Collins, J.; Jackson, W.; Lu, J.; Jury, J.; Deng, Y.K.; Blennerhassett, P.; Macri, J.; McCoy, K.D.; et al. The Intestinal Microbiota Affect Central Levels of Brain-Derived Neurotropic Factor and Behavior in Mice. Gastroenterology 2011, 141, U599-U609. [CrossRef] [PubMed]

145. Clarke, G.; Grenham, S.; Scully, P.; Fitzgerald, P.; Moloney, R.D.; Shanahan, F.; Dinan, T.G.; Cryan, J.F. The microbiome-gut-brain axis during early life regulates the hippocampal serotonergic system in a sex-dependent manner. Mol. Psychiatry 2013, 18, 666-673. [CrossRef] [PubMed]

146. Lee, H.C.; Jenner, A.M.; Low, C.S.; Lee, Y.K. Effect of tea phenolics and their aromatic fecal bacterial metabolites on intestinal microbiota. Res. Microbiol. 2006, 157, 876-884. [CrossRef] [PubMed]

147. Kennedy, P.J.; Murphy, A.B.; Cryan, J.F.; Ross, P.R.; Dinan, T.G.; Stanton, C. Microbiome in brain function and mental health. Trends Food Sci. Technol. 2016, 57, 289-301. [CrossRef]

148. Duda-Chodak, A.; Tarko, T.; Satora, P.; Sroka, P. Interaction of dietary compounds, especially polyphenols, with the intestinal microbiota: A review. Eur. J. Nutr. 2015, 54, 325-341. [CrossRef] [PubMed]

149. Okubo, T.; Ishihara, N.; Oura, A.; Serit, M.; Kim, M.; Yamamoto, T.; Mitsuoka, T. In Vivo Effects of Tea Polyphenol Intake on Human Intestinal Microflora and Metabolism. Biosci. Biotechnol. Biochem. 1992, 56, 588-591. [CrossRef]

150. Yates, A.A.; Erdman, J.W., Jr.; Shao, A.; Dolan, L.C.; Griffiths, J.C. Bioactive nutrients-Time for tolerable upper intake levels to address safety. Regul. Toxicol. Pharmacol. 2017, 84, 94-101. [CrossRef]

151. Axling, U.; Olsson, C.; Xu, J.; Fernandez, C.; Larsson, S.; Strom, K.; Ahrne, S.; Holm, C.; Molin, G.; Berger, K. Green tea powder and Lactobacillus plantarum affect gut microbiota, lipid metabolism and inflammation in high-fat fed C57BL/6J mice. Nutr. Metab. (London) 2012, 9, 105. [CrossRef]

152. Allen, A.P.; Hutch, W.; Borre, Y.E.; Kennedy, P.J.; Temko, A.; Boylan, G.; Murphy, E.; Cryan, J.F.; Dinan, T.G.; Clarke, G. Bifidobacterium longum 1714 as a translational psychobiotic: Modulation of stress, electrophysiology and neurocognition in healthy volunteers. Transl. Psychiatry 2016, 6, e939. [CrossRef] [PubMed]

153. Hara, Y. Influence of tea catechins on the digestive tract. J. Cell. Biochem. 1997, 27, 52-58. [CrossRef]

154. Barrett, E.; Ross, R.P.; O’Toole, P.W.; Fitzgerald, G.F.; Stanton, C. Gamma-Aminobutyric acid production by culturable bacteria from the human intestine. J. Appl. Microbiol. 2012, 113, 411-417. [CrossRef] [PubMed]

155. Bravo, J.A.; Forsythe, P.; Chew, M.V.; Escaravage, E.; Savignac, H.M.; Dinan, T.G.; Bienenstock, J.; Cryan, J.F. Ingestion of Lactobacillus strain regulates emotional behavior and central GABA receptor expression in a mouse via the vagus nerve. Proc. Natl. Acad. Sci. USA 2011, 108, 16050-16055. [CrossRef] [PubMed]

156. Liu, Y.W.; Liong, M.T.; Tsai, Y.C. New perspectives of Lactobacillus plantarum as a probiotic: The gut-heart-brain axis. J. Microbiol. 2018, 56, 601-613. [CrossRef] [PubMed]

157. Strandwitz, P.; Kim, K.H.; Terekhova, D.; Liu, J.K.; Sharma, A.; Levering, J.; McDonald, D.; Dietrich, D.; Ramadhar, T.R.; Lekbua, A.; et al. GABA-modulating bacteria of the human gut microbiota. Nat. Microbiol. 2019, 4, 396-403. [CrossRef] [PubMed]

158. Etxeberria, U.; Fernandez-Quintela, A.; Milagro, F.I.; Aguirre, L.; Martinez, J.A.; Portillo, M.P. Impact of polyphenols and polyphenol-rich dietary sources on gut microbiota composition. J. Agric. Food Chem. 2013, 61, 9517-9533. [CrossRef] [PubMed]

159. dos Santos Pereira Indiani, C.M.; Rizzardi, K.F.; Castelo, P.M.; Caldas Ferraz, L.F.; Darrieux, M.; Parisotto, T.M. Childhood Obesity and Firmicutes/Bacteroidetes Ratio in the Gut Microbiota: A Systematic Review. Child. Obes. 2018, 14, 501-509. [CrossRef] [PubMed]

160. Lambert, J.E.; Myslicki, J.P.; Bomhof, M.R.; Belke, D.D.; Shearer, J.; Reimer, R.A. Exercise training modifies gut microbiota in normal and diabetic mice. Appl. Physiol. Nutr. Metab. 2015, 40, 749-752. [CrossRef]

161. Yatsunenko, T.; Rey, F.E.; Manary, M.J.; Trehan, I.; Dominguez-Bello, M.G.; Contreras, M.; Magris, M.; Hidalgo, G.; Baldassano, R.N.; Anokhin, A.P.; et al. Human gut microbiome viewed across age and geography. Nature 2012, 486, 222-227. [CrossRef]

162. Rothenberg, D.O.; Zhou, C.B.; Zhang, L.Y. A Review on the Weight-Loss Effects of Oxidized Tea Polyphenols. Molecules 2018, 23, 1176. [CrossRef] [PubMed] 
163. Frost, G.; Sleeth, M.L.; Sahuri-Arisoylu, M.; Lizarbe, B.; Cerdan, S.; Brody, L.; Anastasovska, J.; Ghourab, S.; Hankir, M.; Zhang, S.; et al. The short-chain fatty acid acetate reduces appetite via a central homeostatic mechanism. Nat. Commun. 2014, 5, 3611. [CrossRef] [PubMed]

164. Vijay, N.; Morris, M.E. Role of monocarboxylate transporters in drug delivery to the brain. Curr. Pharm. Des. 2014, 20, 1487-1498. [CrossRef] [PubMed]

165. van de Wouw, M.; Boehme, M.; Lyte, J.M.; Wiley, N.; Strain, C.; O’Sullivan, O.; Clarke, G.; Stanton, C.; Dinan, T.G.; Cryan, J.F. Short-chain fatty acids: Microbial metabolites that alleviate stress-induced brain-gut axis alterations. J. Physiol.-Lond. 2018, 596, 4923-4944. [CrossRef] [PubMed]

166. Stilling, R.M.; van de Wouw, M.; Clarke, G.; Stanton, C.; Dinan, T.G.; Cryan, J.F. The neuropharmacology of butyrate: The bread and butter of the microbiota-gut-brain axis? Neurochem. Int. 2016, 99, 110-132. [CrossRef] [PubMed]

167. Odaira, T.; Nakagawasai, O.; Takahashi, K.; Nemoto, W.; Sakuma, W.; Lin, J.-R.; Tan-No, K. Mechanisms underpinning AMP-activated protein kinase-related effects on behavior and hippocampal neurogenesis in an animal model of depression. Neuropharmacology 2019, 150, 121-133. [CrossRef]

168. Bremner, J.D.; Narayan, M.; Anderson, E.R.; Staib, L.H.; Miller, H.L.; Charney, D.S. Hippocampal volume reduction in major depression. Am. J. Psychiatry 2000, 157, 115-117. [CrossRef] [PubMed]

169. Sheline, Y.I. Neuroimaging studies of mood disorder effects on the brain. Biol. Psychiatry 2003, 54, 338-352. [CrossRef]

170. Andrade, J.P.; Rodrigues, J.; Cardoso, A. Protective effects of chronic green tea consumption on dendritic trees during ageing. Agro Food Ind. Hi-Tech 2013, 24, 6-9.

171. Assuncao, M.; Santos-Marques, M.J.; Carvalho, F.; Andrade, J.P. Green tea averts age-dependent decline of hippocampal signaling systems related to antioxidant defenses and survival. Free Radic. Biol. Med. 2010, 48, 831-838. [CrossRef]

172. Assuncao, M.; Santos-Marques, M.J.; Carvalho, F.; Lukoyanov, N.V.; Andrade, J.P. Chronic green tea consumption prevents age-related changes in rat hippocampal formation. Neurobiol. Aging 2011, 32, 707-717. [CrossRef] [PubMed]

173. Liu, X.; Qian, X.; Xing, J.; Wang, J.; Sun, Y.; Wang, Q.G.; Li, H. Particulate Matter Triggers Depressive-Like Response Associated with Modulation of Inflammatory Cytokine Homeostasis and Brain-Derived Neurotrophic Factor Signaling Pathway in Mice. Toxicol. Sci. 2018, 164, 278-288. [CrossRef] [PubMed]

174. Dugan, L.L.; Sensi, S.L.; Canzoniero, L.M.T.; Handran, S.D.; Rotham, S.M.; Lin, T.S.; Goldberg, M.P.; Choi, D.W. Mitochondrial production of reactive oxygen species in cortical neurons following exposure to N-methyl-D-aspartate. J. Neurosci. 1995, 15, 6377-6388. [CrossRef] [PubMed]

175. Black, C.N.; Bot, M.; Scheffer, P.G.; Cuijpers, P.; Penninx, B.W. Is depression associated with increased oxidative stress? A systematic review and meta-analysis. Psychoneuroendocrinology 2015, 51, 164-175. [CrossRef] [PubMed]

176. Mayberg, H.S. Positron emission tomography imaging in depression: A neural systems perspective. Neuroimaging Clin. N. Am. 2003, 13, 805-815. [CrossRef]

177. Wang, L.H.; Labar, K.S.; Smoski, M.; Rosenthal, M.Z.; Dolcos, F.; Lynch, T.R.; Krishnan, R.R.; McCarthy, G. Prefrontal mechanisms for executive control over emotional distraction are altered in major depression. Psychiatry Res.-Neuroimaging 2008, 163, 143-155. [CrossRef] [PubMed]

178. Groenewold, N.A.; Opmeer, E.M.; de Jonge, P.; Aleman, A.; Costafreda, S.G. Emotional valence modulates brain functional abnormalities in depression: Evidence from a meta-analysis of fMRI studies. Neurosci. Biobehav. Rev. 2013, 37, 152-163. [CrossRef] [PubMed]

179. Santarelli, L.; Saxe, M.; Gross, C.; Surget, A.; Battaglia, F.; Dulawa, S.; Weisstaub, N.; Lee, J.; Duman, R.; Arancio, O.; et al. Requirement of hippocampal neurogenesis for the behavioral effects of antidepressants. Science 2003, 301, 805-809. [CrossRef]

180. Zagrebelsky, M.; Korte, M. Form follows function: BDNF and its involvement in sculpting the function and structure of synapses. Neuropharmacology 2014, 76, 628-638. [CrossRef]

181. Monteleone, P.; Serritella, C.; Martiadis, V.; Maj, M. Decreased levels of serum brain-derived neurotrophic factor in both depressed and euthymic patients with unipolar depression and in euthymic patients with bipolar I and II disorders. Bipolar Disord. 2008, 10, 95-100. [CrossRef] 
182. Taliaz, D.; Stall, N.; Dar, D.E.; Zangen, A. Knockdown of brain-derived neurotrophic factor in specific brain sites precipitates behaviors associated with depression and reduces neurogenesis. Mol. Psychiatry 2010, 15, 80-92. [CrossRef] [PubMed]

183. Nitta, A.; Ohmiya, M.; Sometani, A.; Itoh, M.; Nomoto, H.; Furukawa, Y.; Furukawa, S. Brain-derived neurotrophic factor prevents neuronal cell death induced by corticosterone. J. Neurosci. Res. 1999, 57, $227-235$. [CrossRef]

184. Lee, J.; Duan, W.; Mattson, M.P. Evidence that brain-derived neurotrophic factor is required for basal neurogenesis and mediates, in part, the enhancement of neurogenesis by dietary restriction in the hippocampus of adult mice. J. Neurochem. 2002, 82, 1367-1375. [CrossRef] [PubMed]

185. Shimizu, E.; Hashimoto, K.; Iyo, M. Major depressive disorders and BDNF (brain-derived neurotrophic factor). Nihon Shinkei Seishin Yakurigaku Zasshi = Jpn. J. Psychopharmacol. 2004, 24, 147-150.

186. Duman, R.S.; Monteggia, L.M. A neurotrophic model for stress-related mood disorders. Biol. Psychiatry 2006, 59, 1116-1127. [CrossRef] [PubMed]

187. Hashimoto, K.; Shimizu, E.; Iyo, M. Critical role of brain-derived neurotrophic factor in mood disorders. Brain Res. Rev. 2004, 45, 104-114. [CrossRef] [PubMed]

188. Takeda, A.; Sakamoto, K.; Tamano, H.; Fukura, K.; Inui, N.; Suh, S.W.; Won, S.-J.; Yokogoshi, H. Facilitated Neurogenesis in the Developing Hippocampus After Intake of Theanine, an Amino Acid in Tea Leaves, and Object Recognition Memory. Cell. Mol. Neurobiol. 2011, 31, 1079-1088. [CrossRef] [PubMed]

189. Ortiz-Lopez, L.; Marquez-Valadez, B.; Gomez-Sanchez, A.; Silva-Lucero, M.D.C.; Torres-Perez, M.; Tellez-Ballesteros, R.I.; Ichwan, M.; Meraz-Rios, M.A.; Kempermann, G.; Ramirez-Rodriguez, G.B. Green Tea Compound Epigallo-Catechin-3-Gallate (Egcg) Increases Neuronal Survival in Adult Hippocampal Neurogenesis in Vivo and in Vitro. Neuroscience 2016, 322, 208-220. [CrossRef]

190. Gundimeda, U.; McNeill, T.H.; Fan, T.K.; Deng, R.; Rayudu, D.; Chen, Z.; Cadenas, E.; Gopalakrishna, R. Green tea catechins potentiate the neuritogenic action of brain-derived neurotrophic factor: Role of $67-\mathrm{kDa}$ laminin receptor and hydrogen peroxide. Biochem. Biophys. Res. Commun. 2014, 445, 218-224. [CrossRef]

191. Feng, S.; Liu, J.; Cheng, B.; Deng, A.P.; Zhang, H. (-)-Epigallocatechin-3-gallate protects PC12 cells against corticosterone-induced neurotoxicity via the hedgehog signaling pathway. Exp. Ther. Med. 2018, 15, 4284-4290. [CrossRef]

192. Pervin, M.; Unno, K.; Nakagawa, A.; Takahashi, Y.; Iguchi, K.; Yamamoto, H.; Hoshino, M.; Hara, A.; Takagaki, A.; Nanjo, F.; et al. Blood brain barrier permeability of (-)-epigallocatechin gallate, its proliferation-enhancing activity of human neuroblastoma SH-SY5Y cells, and its preventive effect on age-related cognitive dysfunction in mice. Biochem. Biophys. Rep. 2017, 9, 180-186. [CrossRef] [PubMed]

193. Ding, M.-1.; Ma, H.; Man, Y.-G.; Lv, H.-Y. Protective effects of a green tea polyphenol, epigallocatechin-3-gallate, against sevoflurane-induced neuronal apoptosis involve regulation of CREB/BDNF/TrkB and PI3K/Akt/mTOR signalling pathways in neonatal mice. Can. J. Physiol. Pharmacol. 2017, 95, 1396-1405. [CrossRef] [PubMed]

194. Nath, S.; Bachani, M.; Harshavardhana, D.; Steiner, J.P. Catechins protect neurons against mitochondrial toxins and HIV proteins via activation of the BDNF pathway. J. Neurovirol. 2012, 18, 445-455. [CrossRef] [PubMed]

195. Tian, W.; Han, X.-G.; Liu, Y.-J.; Tang, G.-Q.; Liu, B.; Wang, Y.-Q.; Xiao, B.; Xu, Y.-F. Intrathecal Epigallocatechin Gallate Treatment Improves Functional Recovery After Spinal Cord Injury by Upregulating the Expression of BDNF and GDNF. Neurochem. Res. 2013, 38, 772-779. [CrossRef] [PubMed]

196. Unno, K.; Pervin, M.; Nakagawa, A.; Iguchi, K.; Hara, A.; Takagaki, A.; Nanjo, F.; Minami, A.; Nakamura, Y. Blood-Brain Barrier Permeability of Green Tea Catechin Metabolites and their Neuritogenic Activity in Human Neuroblastoma SH-SY5Y Cells. Mol. Nutr. Food Res. 2017, 61. [CrossRef] [PubMed]

197. Rodrigues, J.; Assuncao, M.; Lukoyanov, N.; Cardoso, A.; Carvalho, F.; Andrade, J.P. Protective effects of a catechin-rich extract on the hippocampal formation and spatial memory in aging rats. Behav. Brain Res. 2013, 246, 94-102. [CrossRef] [PubMed]

198. Moghadas, M.; Edalatmanesh, M.A.; Robati, R. Histopathological Analysis from Gallic Acid Administration on Hippocampal Cell Density, Depression, and Anxiety Related Behaviors in A Trimethyltin Intoxication Model. Cell J. 2016, 17, 659-667. [PubMed]

199. Zhou, H.; Li, X.J.; Gao, M. Curcumin Protects PC12 Cells from Corticosterone-Induced Cytotoxicity: Possible Involvement of the ERK 1/2 Pathway (vol 104, pg 236, 2009). Basic Clin. Pharmacol. Toxicol. 2009, 104, 417. 
200. Bhattacharya, T.K.; Pence, B.D.; Ossyra, J.M.; Gibbons, T.E.; Perez, S.; McCusker, R.H.; Kelley, K.W.; Johnson, R.W.; Woods, J.A.; Rhodes, J.S. Exercise but not (-)-epigallocatechin-3-gallate or beta-alanine enhances physical fitness, brain plasticity, and behavioral performance in mice. Physiol. Behav. 2015, 145, 29-37. [CrossRef] [PubMed]

201. Nair, A.B.; Jacob, S. A simple practice guide for dose conversion between animals and human. J. Basic Clin. Pharm. 2016, 7, 27-31. [CrossRef] [PubMed]

202. Pervin, M.; Unno, K.; Ohishi, T.; Tanabe, H.; Miyoshi, N.; Nakamura, Y. Beneficial Effects of Green Tea Catechins on Neurodegenerative Diseases. Molecules 2018, 23, 1297. [CrossRef] [PubMed]

203. Guedj, F.; Sebrie, C.; Rivals, I.; Ledru, A.; Paly, E.; Bizot, J.C.; Smith, D.; Rubin, E.; Gillet, B.; Arbones, M.; et al. Green Tea Polyphenols Rescue of Brain Defects Induced by Overexpression of DYRK1A. PLoS ONE 2009, 4, e4606. [CrossRef] [PubMed]

204. Lyubomirsky, S.; King, L.; Diener, E. The benefits of frequent positive affect: Does happiness lead to success? Psychol. Bull. 2005, 131, 803-855. [CrossRef] [PubMed]

205. Baas, M.; de Dreu, C.K.W.; Nijstad, B.A. A Meta-Analysis of 25 Years of Mood-Creativity Research: Hedonic Tone, Activation, or Regulatory Focus? Psychol. Bull. 2008, 134, 779-806. [CrossRef] [PubMed]

206. Cohen, A.O.; Dellarco, D.V.; Breiner, K.; Helion, C.; Heller, A.S.; Rahdar, A.; Pedersen, G.; Chein, J.; Dyke, J.P.; Galvan, A.; et al. The Impact of Emotional States on Cognitive Control Circuitry and Function. J. Cogn. Neurosci. 2016, 28, 446-459. [CrossRef]

207. Froeber, K.; Dreisbach, G. The differential influences of positive affect, random reward, and performance-contingent reward on cognitive control. Cogn. Affect. Behav. Neurosci. 2014, 14, 530-547. [CrossRef]

208. Vanlessen, N.; De Raedt, R.; Mueller, S.C.; Rossi, V.; Pourtois, G. Happy and less inhibited? Effects of positive mood on inhibitory control during an antisaccade task revealed using topographic evoked potential mapping. Biol. Psychol. 2015, 110, 190-200. [CrossRef]

209. Dolcos, F.; Iordan, A.D.; Dolcos, S. Neural correlates of emotion-cognition interactions: A review of evidence from brain imaging investigations. J. Cogn. Psychol. (Hove) 2011, 23, 669-694. [CrossRef]

210. Ritchey, M.; Dolcos, F.; Eddington, K.M.; Strauman, T.J.; Cabeza, R. Neural correlates of emotional processing in depression: Changes with cognitive behavioral therapy and predictors of treatment response. J. Psychiatr. Res. 2011, 45, 577-587. [CrossRef]

211. Steptoe, A.; Wardle, J. Positive affect and biological function in everyday life. Neurobiol. Aging 2005, 26, S108-S112. [CrossRef]

212. Turner, M.A.; Andrewes, D.G. The relationship between mood state, interpersonal attitudes and psychological distress in stroke patients. International journal of rehabilitation research. Internationale Zeitschrift fur Rehabilitationsforschung. Revue Internationale de Recherches de Readaptation 2010, 33, 43-48. [PubMed]

213. Einöther, S.J.; Martens, V.E. Acute effects of tea consumption on attention and mood. Am. J. Clin. Nutr. 2013, 98, 1700S-1708S. [CrossRef] [PubMed]

214. Bryan, J. Psychological effects of dietary components of tea: Caffeine and L-theanine. Nutr. Rev. 2008, 66, 82-90. [CrossRef]

215. Kahathuduwa, C.N.; Dhanasekara, C.S.; Chin, S.H.; Davis, T.; Weerasinghe, V.S.; Dassanayake, T.L.; Binks, M. L-Theanine and caffeine improve target-specific attention to visual stimuli by decreasing mind wandering: A human functional magnetic resonance imaging study. Nutr. Res. 2018, 49, 67-78. [CrossRef] [PubMed]

216. Dietz, C.; Dekker, M.; Piqueras-Fiszman, B. An intervention study on the effect of matcha tea, in drink and snack bar formats, on mood and cognitive performance. Food Res. Int. 2017, 99, 72-83. [CrossRef]

217. Wightman, E.L.; Haskell, C.F.; Forster, J.S.; Veasey, R.C.; Kennedy, D.O. Epigallocatechin gallate, cerebral blood flow parameters, cognitive performance and mood in healthy humans: A double-blind, placebo-controlled, crossover investigation. Hum. Psychopharmacol.-Clin. Exp. 2012, 27, 177-186. [CrossRef] [PubMed]

218. Scholey, A.; Downey, L.A.; Ciorciari, J.; Pipingas, A.; Nolidin, K.; Finn, M.; Wines, M.; Catchlove, S.; Terrens, A.; Barlow, E.; et al. Acute neurocognitive effects of epigallocatechin gallate (EGCG). Appetite 2012, 58, 767-770. [CrossRef]

219. Einöther, S.J.L.; Baas, M.; Rowson, M.; Giesbrecht, T. Investigating the effects of tea, water and a positive affect induction on mood and creativity. Food Qual. Prefer. 2015, 39, 56-61. [CrossRef]

220. Einother, S.J.L.; Rowson, M.; Ramaekers, J.G.; Giesbrecht, T. Infusing pleasure: Mood effects of the consumption of a single cup of tea. Appetite 2016, 103, 302-308. [CrossRef] 
221. Dohle, S.; Rail, S.; Siegrist, M. I cooked it myself: Preparing food increases liking and consumption. Food Qual. Prefer. 2014, 33, 14-16. [CrossRef]

222. Vohs, K.D.; Wang, Y.; Gino, F.; Norton, M.I. Rituals enhance consumption. Psychol. Sci. 2013, 24, $1714-1721$. [CrossRef] [PubMed]

223. Burgdorf, J.; Panksepp, J. The neurobiology of positive emotions. Neurosci. Biobehav. Rev. 2006, 30, $173-187$. [CrossRef] [PubMed]

224. Berridge, K.C.; Robinson, T.E. Parsing reward. Trends Neurosci. 2003, 26, 507-513. [CrossRef]

225. Dawkins, L.; Shahzad, F.-Z.; Ahmed, S.S.; Edmonds, C.J. Expectation of having consumed caffeine can improve performance and mood. Appetite 2011, 57, 597-600. [CrossRef] [PubMed]

226. Williams, L.E.; Bargh, J.A. Experiencing physical warmth promotes interpersonal warmth. Science 2008, 322, 606-607. [CrossRef] [PubMed]

227. Inagaki, T.K.; Irwin, M.R.; Moieni, M.; Jevtic, I.; Eisenberger, N.I. A Pilot Study Examining Physical and Social Warmth: Higher (Non-Febrile) Oral Temperature Is Associated with Greater Feelings of Social Connection. PLoS ONE 2016, 11, e0156873. [CrossRef] [PubMed]

228. Willemse, C.J.A.M.; Heylen, D.K.J.; van Erp, J.B.F. Communication via warm haptic interfaces does not increase social warmth. J. Multimodal User Interfaces 2018, 12, 329-344. [CrossRef]

229. Dubovski, N.; Ert, E.; Niv, M.Y. Bitter mouth-rinse affects emotions. Food Qual. Prefer. 2017, 60, $154-164$. [CrossRef]

230. Wiener, A.; Shudler, M.; Levit, A.; Niv, M.Y. BitterDB: A database of bitter compounds. Nucleic Acids Res. 2012, 40, D413-D419. [CrossRef]

231. Di Pizio, A.; Niv, M.Y. Computational Studies of Smell and Taste Receptors. Isr. J. Chem. 2014, 54, 1205-1218. [CrossRef]

232. Di Pizio, A.; Niv, M.Y. Promiscuity and selectivity of bitter molecules and their receptors. Bioorg. Med. Chem. 2015, 23, 4082-4091. [CrossRef] [PubMed]

233. Bobowski, N.; Reed, D.R.; Mennella, J.A. Variation in the TAS2R31 bitter taste receptor gene relates to liking for the nonnutritive sweetener Acesulfame-K among children and adults. Sci. Rep. 2016, 6, 39135. [CrossRef] [PubMed]

234. Roura, E.; Aldayyani, A.; Thavaraj, P.; Prakash, S.; Greenway, D.; Thomas, W.G.; Meyerhof, W.; Roudnitzky, N.; Foster, S.R. Variability in Human Bitter Taste Sensitivity to Chemically Diverse Compounds Can Be Accounted for by Differential TAS2R Activation. Chem. Senses 2015, 40, 427-435. [CrossRef] [PubMed]

235. Mennella, J.A.; Bobowski, N.K. The sweetness and bitterness of childhood: Insights from basic research on taste preferences. Physiol. Behav. 2015, 152, 502-507. [CrossRef]

236. Weisburger, J.H. Tea and health: A historical perspective. Cancer Lett. 1997, 114, 315-317. [CrossRef]

237. Korir, M.W.; Wachira, F.N.; Wanyoko, J.K.; Ngure, R.M.; Khalid, R. The fortification of tea with sweeteners and milk and its effect on in vitro antioxidant potential of tea product and glutathione levels in an animal model. Food Chem. 2014, 145, 145-153. [CrossRef]

238. Lorenz, M.; Jochmann, N.; von Krosigk, A.; Martus, P.; Baumann, G.; Stangl, K.; Stangl, V. Addition of milk prevents vascular protective effects of tea. Eur. Heart J. 2007, 28, 219-223. [CrossRef]

239. Gose, M.; Krems, C.; Heuer, T.; Hoffmann, I. Trends in food consumption and nutrient intake in Germany between 2006 and 2012: Results of the German National Nutrition Monitoring (NEMONIT). Br. J. Nutr. 2016, 115, 1498-1507. [CrossRef]

240. Drewnowski, A.; Rehm, C.D. Sources of Caffeine in Diets of US Children and Adults: Trends by Beverage Type and Purchase Location. Nutrients 2016, 8, 154. [CrossRef]

241. Del Rio, D.; Calani, L.; Cordero, C.; Salvatore, S.; Pellegrini, N.; Brighenti, F. Bioavailability and catabolism of green tea flavan-3-ols in humans. Nutrition 2010, 26, 1110-1116. [CrossRef]

242. Manach, C.; Williamson, G.; Morand, C.; Scalbert, A.; Remesy, C. Bioavailability and bioefficacy of polyphenols in humans. I. Review of 97 bioavailability studies. Am. J. Clin. Nutr. 2005, 81, 230S-242S. [CrossRef] [PubMed]

243. Stalmach, A.; Troufflard, S.; Serafini, M.; Crozier, A. Absorption, metabolism and excretion of Choladi green tea flavan-3-ols by humans. Mol. Nutr. Food Res. 2009, 53, S44-S53. [CrossRef] [PubMed]

244. Selma, M.V.; Espin, J.C.; Tomas-Barberan, F.A. Interaction between Phenolics and Gut Microbiota: Role in Human Health. J. Agric. Food Chem. 2009, 57, 6485-6501. [CrossRef] [PubMed] 
245. Li, D.; Wang, P.; Wang, P.; Hu, X.; Chen, F. The gut microbiota: A treasure for human health. Biotechnol. Adv. 2016, 34, 1210-1224. [CrossRef] [PubMed]

246. Carlos Espin, J.; Gonzalez-Sarrias, A.; Tomas-Barberan, F.A. The gut microbiota: A key factor in the therapeutic effects of (poly) phenols. Biochem. Pharmacol. 2017, 139, 82-93. [CrossRef] [PubMed]

247. Oteiza, P.I.; Fraga, C.G.; Mills, D.A.; Taft, D.H. Flavonoids and the gastrointestinal tract: Local and systemic effects. Mol. Asp. Med. 2018, 61, 41-49. [CrossRef] [PubMed]

248. Shang, Z.; Wang, F.; Dai, S.; Lu, J.; Wu, X.; Zhang, J. Profiling and identification of (-)-epicatechin metabolites in rats using ultra-high performance liquid chromatography coupled with linear trap-Orbitrap mass spectrometer. Drug Test. Anal. 2017, 9, 1224-1235. [CrossRef]

249. Borges, G.; Ottaviani, J.I.; van der Hooft, J.J.J.; Schroeter, H.; Crozier, A. Absorption, metabolism, distribution and excretion of (-)-epicatechin: A review of recent findings. Mol. Asp. Med. 2018, 61, 18-30. [CrossRef]

250. Wang, J.; Ferruzzi, M.G.; Ho, L.; Blount, J.; Janle, E.M.; Gong, B.; Pan, Y.; Gowda, G.A.N.; Raftery, D.; Arrieta-Cruz, I.; et al. Brain-Targeted Proanthocyanidin Metabolites for Alzheimer's Disease Treatment. J. Neurosci. 2012, 32, 5144-5150. [CrossRef]

251. Schimidt, H.L.; Garcia, A.; Martins, A.; Mello-Carpes, P.B.; Carpes, F.P. Green tea supplementation produces better neuroprotective effects than red and black tea in Alzheimer-like rat model. Food Res. Int. 2017, $100 \mathrm{Pt}$ 1, 442-448. [CrossRef]

252. Wang, Y.; Kan, Z.; Thompson, H.J.; Ling, T.; Ho, C.-T.; Li, D.; Wan, X. Impact of Six Typical Processing Methods on the Chemical Composition of Tea Leaves Using a Single Camellia sinensis Cultivar, Longjing 43. J. Agric. Food Chem. 2018. [CrossRef] [PubMed]

253. Lin, J.-K.; Lin, C.-L.; Liang, Y.-C.; Lin-Shiau, S.-Y.; Juan, I.M. Survey of catechins, gallic acid, and methylxanthines in green, oolong, pu-erh, and black teas. J. Agric. Food Chem. 1998, 46, 3635-3642. [CrossRef]

254. Lee, V.S.Y.; Dou, J.; Chen, R.J.Y.; Lin, R.-S.; Lee, M.-R.; Tzen, J.T.C. Massive accumulation of gallic acid and unique occurrence of myricetin, quercetin, and kaempferol in preparing old oolong tea. J. Agric. Food Chem. 2008, 56, 7950-7956. [CrossRef] [PubMed]

255. Teng, J.; Zhou, W.; Zeng, Z.; Zhao, W.; Huang, Y.; Zhang, X. Quality components and antidepressant-like effects of GABA green tea. Food Funct. 2017, 8, 3311-3318. [CrossRef] [PubMed] 